\title{
Novel triazoles of 3-acetylbetulin and betulone as anticancer agents
}

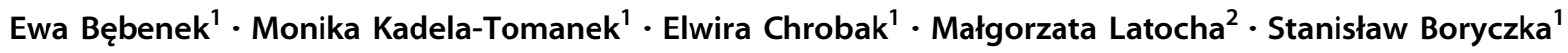

Received: 13 April 2018 / Accepted: 27 June 2018 / Published online: 17 July 2018

(c) The Author(s) 2018

\begin{abstract}
The CuAAC reaction of azides and acetylenic triterpenes was used for synthesis of new triazoles of 3-acetylbetulin and betulone. The triazole derivatives were evaluated for their anticancer activity in vitro against amelanotic melanoma C-32, ductal carcinoma T47D and glioblastoma SNB-19 cell lines. 28-[1-(3'-Deoxythymidine-5'-yl)-1H-1,2,3-triazol-4-yl] carbonylbetulone 6e exhibited a significant $\mathrm{IC}_{50}$ value $(0.17 \mu \mathrm{M})$ against the human glioblastoma SNB-19 cell line, an almost 5-fold higher potency while compared with reference cisplatin.
\end{abstract}

Keywords Betulin $\cdot 1,2,3$-Triazole $\cdot \mathrm{CuAAC} \cdot$ Anticancer activity $\cdot$ Lipophilicity

\section{Introduction}

The cycloaddition reaction plays an important role in the synthesis of five-membered heterocyclic structures such as 1,2,3-triazoles. Molecules containing a 1,4-disubstituted 1,2,3-triazole ring are prepared regioselectively from azides and terminal alkynes in the copper-(I)-catalyzed azidealkyne cycloaddition reaction CuAAC (Wei et al. 2012; Marciniec et al. 2017). CuAAC reactions, described by Sharpless and Meldal groups, give high yields under mild conditions and have been used to obtain drugs, photo stabilizers and dyes. Additionally, this reaction occurs in various organic solvents and in aqueous media, in a wide $\mathrm{pH}$ area. In contrast to the CuACC reaction, the ruthenium catalyst azide-alkyne cycloaddition is used in the synthesis of the 1,5-disubstituted triazoles (Rostovtsev et al. 2002; Torne et al. 2002; Bonacorso et al. 2013; Bräse et al. 2008; Totobenazara et al. 2015).

Ewa Bębenek

ebebenek@sum.edu.pl

1 Department of Organic Chemistry, School of Pharmacy with the Division of Laboratory Medicine in Sosnowiec, Medical University of Silesia in Katowice, 4 Jagiellońska Str., 41-200 Sosnowiec, Poland

2 Department of Cell Biology, School of Pharmacy with the Division of Laboratory Medicine in Sosnowiec, Medical University of Silesia in Katowice, 8 Jedności Str., 41-200 Sosnowiec, Poland
Compounds containing 1,2,3-triazole units exhibit interesting biological activities (antimicrobial, anti-inflammatory, anti-tubercular, and antiviral), which has found numerous applications in bioconjugate chemistry and material science. Additionally, 1,4-disubstitued 1,2,3-triazoles show a significant anticancer activity against human cancer cell lines, which are multidrug-resistant (Wang et al. 2010; Dheer et al. 2017; He et al. 2014).

In the last decades, application of 1,3-dipolar cycloaddiction of naturally occurring triterpenes acquired meaning. Conjugation on azides with various alkyne derivatives of pentacyclic triterpenes is designed for the purposes of introduction of the physiologically stable 1,2,3-triazole group (Spivak et al. 2016; Suman et al. 2016; Yu et al. 2013). Most of the triazole analogs of natural compounds have been investigated for their anticancer activity. Majeed et al. synthesized and tested a series of C-3 aryl-substituted 1,2,3-triazoles of betulinic acid for their cytotoxic activity against various human cancer lines like leukemia (HL-60, THP-1), prostate (DU-145, PC-3), lung (A-549), breast (MCF-7), liver (HEP-2), colon (HCT-15), and neuroblastoma (SF-295). The compounds bearing 2-cyanophenyl and 5-hydroxy-1-naphthyl substituted triazole ring exhibited promising $\mathrm{IC}_{50}$ values against HL-60 cell line of 2.5 and $3.5 \mu \mathrm{M}$, respectively, in comparison to betulinic acid $\left(\mathrm{IC}_{50}=17 \mu \mathrm{M}\right)$ (Majeed et al. 2013). In the case of C-28 aryl-substituted 1,2,3-triazoles of betulinic acid, it was observed that compounds containing a 4-fluorophenyl substituted triazole ring had the cytotoxic profile similar to that of betulinic acid. This novel triazole hybrid showed a significant antiproliferative activity in HL-60 (leukemia), 
Table 1 The mobile phases used in column chromatography and calculated values of the retention factor

\begin{tabular}{llll}
\hline Compound & $\mathrm{Mobile}$ phase & Ratio & Retention factor $\mathrm{R}_{\mathrm{f}}$ \\
\hline $\mathbf{5 a}$ & $\mathrm{CH}_{2} \mathrm{Cl}_{2}-\mathrm{EtOH}$ & $60: 1$ & 0.39 \\
$\mathbf{5 b}$ & $\mathrm{CH}_{2} \mathrm{Cl}_{2}-\mathrm{EtOH}$ & $40: 1$ & 0.55 \\
$\mathbf{5 c}$ & $\mathrm{CH}_{2} \mathrm{Cl}_{2}-\mathrm{EtOH}$ & $60: 1$ & 0.32 \\
$\mathbf{5 d}$ & $\mathrm{CH}_{2} \mathrm{Cl}_{2}-\mathrm{EtOH}$ & $60: 1$ & 0.43 \\
$\mathbf{5 e}$ & $\mathrm{CHCl}_{3}-\mathrm{EtOH}$ & $5: 1$ & 0.68 \\
$\mathbf{5 f}$ & $\mathrm{CHCl}_{3}-\mathrm{EtOH}$ & $5: 1$ & 0.18 \\
$\mathbf{5 g}$ & $\mathrm{CH}_{2} \mathrm{Cl}_{2}-\mathrm{EtOH}$ & $40: 1$ & 0.43 \\
$\mathbf{5 h}$ & $\mathrm{CHCl}_{3}-\mathrm{EtOH}$ & $15: 1$ & 0.45 \\
$\mathbf{5 i}$ & $\mathrm{CHCl}_{3}-\mathrm{EtOH}$ & $5: 1$ & 0.73 \\
$\mathbf{6 a}$ & $\mathrm{CH}_{2} \mathrm{Cl}_{2}-\mathrm{EtOH}$ & $40: 1$ & 0.43 \\
$\mathbf{6 b}$ & $\mathrm{CH}_{2} \mathrm{Cl}_{2}-\mathrm{EtOH}$ & $40: 1$ & 0.49 \\
$\mathbf{6 c}$ & $\mathrm{CH}_{2} \mathrm{Cl}_{2}-\mathrm{EtOH}$ & $60: 1$ & 0.36 \\
$\mathbf{6 d}$ & $\mathrm{CH}_{2} \mathrm{Cl}_{2}-\mathrm{EtOH}$ & $60: 1$ & 0.37 \\
6e & $\mathrm{CHCl}_{3}-\mathrm{EtOH}$ & $15: 1$ & 0.24 \\
6f & $\mathrm{CHCl}_{3}-\mathrm{EtOH}$ & $5: 1$ & 0.22 \\
6g & $\mathrm{CH}_{2} \mathrm{Cl}_{2}-\mathrm{EtOH}$ & $60: 1$ & 0.31 \\
6h & $\mathrm{CHCl}_{3}-\mathrm{EtOH}$ & $15: 1$ & 0.32 \\
6i & $\mathrm{CHCl}_{3}-\mathrm{EtOH}$ & $5: 1$ & 0.74 \\
$\mathbf{6 j}$ & $\mathrm{CHCl}_{3}-\mathrm{EtOH}$ & $5: 1$ & 0.20 \\
\hline
\end{tabular}

MIAPACa2 (pancreas), PC-3 (prostate), and A-549 (lung) cell lines, with $\mathrm{IC}_{50}$ values in the range of $5.0-7.0 \mu \mathrm{M}$ (Khan et al. 2016).

Previously, we described a synthetic route and evaluation of cytotoxicity of betulin and betulone derivatives with a propynoyl group at the C-28 position (Boryczka et al. 2013; Bębenek et al. 2016). Expanding our interest to propynoylsubstituted triterpenes, we converted those acetylenic derivatives into the corresponding 1,2,3-triazoles. In this work, we presented application of the CuAAC reaction in the synthesis of new triazoles of pentacyclic triterpenes and their anticancer activity, as well as lipophilicity properties.

\section{Material and methods}

\section{General}

All organic solvents (from Sigma-Aldrich and P.P.H. STANLAB) were dried and used after purification. Melting points (m.p.) were determined in open capillary tubes on an Electrothermal IA 9300 melting point apparatus and are uncorrected. The ${ }^{1} \mathrm{H}$ NMR and ${ }^{13} \mathrm{C}$ NMR spectra were recorded on a Bruker Avance III 600 spectrometer in deuterated- $\mathrm{d}_{6}$ chloroform $\left(\mathrm{CDCl}_{3}\right)$ or deuterated $-\mathrm{d}_{6}$ dimethyl sulfoxide (DMSO) solution. The chemical shifts were reported in ppm $(\delta)$, and coupling constant $(J)$ values-in hertz $(\mathrm{Hz})$. The spin multiplicity was designated as the singlet (s), doublet (d), triplet (t), quartet (q), and multiplet (m). High-resolution mass spectra (HR-MS) were recorded on a Bruker Impact II instrument. Infrared spectra (IR) were recorded on a Shimadzu IRAffinity-1 FTIR spectrophotometer (Shimadzu, Japan) using the $\mathrm{KBr}$ pellet method. The progress of the reactions was monitored by thin layer chromatography (TLC) using silica gel $60254 \mathrm{~F}$ plates (Merck, Darmstadt, Germany) and detected by spraying with a solution of 5\% sulfuric (VI) acid and heating to $120^{\circ}$ C. Purity of the obtained compounds was confirmed by column chromatography carried out on silica gel 60, $<63 \mu \mathrm{m}$ (Merck). A mixture of $\mathrm{CHCl}_{3}-\mathrm{EtOH}$ (40:1, 15:1, $5: 1 \mathrm{v} / \mathrm{v})$ or $\mathrm{CH}_{2} \mathrm{Cl}_{2}-\mathrm{EtOH}(60: 1,40: 1$, v/v) was used as the mobile phase.

\section{Chemistry}

\section{Synthesis of 3-acetyl-28-propynoylbetulin 3 and 28-} propynoylbetulone 4

3-Acetyl-28-propynoylbetulin $\mathbf{3}$ was prepared according to the procedure described by Boryczka et al. (Boryczka et al. 2013).

To an ice-cooled $\left(-10^{\circ} \mathrm{C}\right)$ mixture of 3-acetylbetulin 2 $(0.48 \mathrm{~g}, 1 \mathrm{mmol})$ and propynoic acid $(0.12 \mathrm{~g}, 1.10 \mathrm{mmol})$ in dichloromethane $(5 \mathrm{~mL})$, a freshly prepared solution of dicyclohexylcarbodiimide $(0.23 \mathrm{~g}, 1.12 \mathrm{mmol})$ and 4 dimethylaminopyridine $(0.01 \mathrm{~g}, 0.08 \mathrm{mmol})$ in dichloromethane $(1 \mathrm{~mL})$ was added. The mixture was allowed to react under argon atmosphere at $-10^{\circ} \mathrm{C}$ for $5 \mathrm{~h}$. After warming to room temperature, the mixture was stirred overnight. The reaction was monitored by TLC until completion. The resulting precipitate was filtered and the solvent was removed under reduced pressure. The crude product was purified by silica gel column chromatography $\left(\mathrm{CHCl}_{3}-\mathrm{EtOH} 40: 1, \mathrm{v} / \mathrm{v}\right)$.

3-Acetyl-28-propynoylbetulin (3) Yield 79\%; $\mathrm{mp}$ $115-118{ }^{\circ} \mathrm{C} ; \mathrm{R}_{\mathrm{f}} 0.44\left(\mathrm{CHCl}_{3}-\mathrm{EtOH}, 40: 1, \mathrm{v} / \mathrm{v}\right) ; \mathrm{IR}(\mathrm{KBr})$ $\nu_{\max } 3304,2946,2120,1719,1457,1246 \mathrm{~cm}^{-1} ;{ }^{1} \mathrm{H} \mathrm{NMR}$ $\left(600 \mathrm{MHz}, \mathrm{CDCl}_{3}\right): \delta 0.81\left(3 \mathrm{H}, \mathrm{s}, \mathrm{CH}_{3}\right), 0.86\left(3 \mathrm{H}, \mathrm{s}, \mathrm{CH}_{3}\right)$, $0.87\left(3 \mathrm{H}, \mathrm{s}, \mathrm{CH}_{3}\right), 0.99\left(3 \mathrm{H}, \mathrm{s}, \mathrm{CH}_{3}\right), 1.05\left(3 \mathrm{H}, \mathrm{s}, \mathrm{CH}_{3}\right)$, $2.07\left(3 \mathrm{H}, \mathrm{s}, \mathrm{COCH}_{3}\right), 2.45(1 \mathrm{H}, \mathrm{m}, \mathrm{H}-19), 2.91(1 \mathrm{H}, \mathrm{s}$, $\mathrm{C} \equiv \mathrm{CH}), 4.01(1 \mathrm{H}, \mathrm{d}, J=10.8 \mathrm{~Hz}, \mathrm{H}-28), 4.41(1 \mathrm{H}, \mathrm{d}, J=$ $10.8 \mathrm{~Hz}, \mathrm{H}-28), 4.48$ (1H, m, H-3), $4.62(1 \mathrm{H}, \mathrm{s}, \mathrm{H}-29), 4.71$ $(1 \mathrm{H}, \mathrm{s}, \mathrm{H}-29) ;{ }^{13} \mathrm{C}$ NMR $\left(150 \mathrm{MHz}, \mathrm{CDCl}_{3}\right): \delta 14.7,16.0$, $16.2,16.5,18.2,19.1,20.8,21.3,23.7,25.1,27.0,27.9$, $29.5,29.6,34.1,34.4,37.1,37.7,37.8,38.4,40.9,42.7$, 46.4, 47.7, 48.8, 50.3, 55.4, 64.9, 74.6, 74.8, 80.9, 110.0, 149.9, 153.3, 171.0; HRAPCIMS $m / z: 536.3878 \mathrm{C}_{35} \mathrm{H}_{52} \mathrm{O}_{4}$ (calcd. 536.3865).

28-Propynoylbetulone 4 was obtained according to the procedure described by Bębenek et al. The spectra data of 
acetylenic ester 4 were consistent with those published in the literature (Bębenek et al. 2016).

\section{General procedure for the synthesis of triazoles $5 a-i$ and $6 a-j$}

Based on the previously reported method, the acetylenic esters 3-4 were converted into triazoles $5 \mathbf{a}-\mathbf{i}$ and $\mathbf{6 a - j}$ by reactions with organic azides in toluene in the presence of copper(I) iodide (Bębenek et al. 2017). The copper(I) iodide $(0.1 \mathrm{eqv}, 0.004 \mathrm{~g}, 0.02 \mathrm{mmol})$ and the organic azide $(1.05$ eqv, $0.21 \mathrm{mmol}$ ) were added to a solution of propynoylated derivatives 3 or $4(0.20 \mathrm{mmol})$ in toluene $(4 \mathrm{~mL})$. Next, the reaction mixture was stirred for another $72 \mathrm{~h}$ under reflux. The solvent was evaporated. The crude residue was purified by silica gel column chromatography using various mixtures of organic solvents. The same mobile phases were applied for TLC and in column chromatography (Table 1).

\section{3-Acetyl-28-(1-benzyl-1H-1,2,3-triazol-4-yl)carbonylbetulin}

(5a) Yield $73 \%$; m.p. $109-111^{\circ} \mathrm{C}$; IR (KBr) $\nu_{\max } 3134$, 2947, 1732, 1527, 1456, 1246-1193 $\mathrm{cm}^{-1}$; ${ }^{1} \mathrm{H}$ NMR $\left(600 \mathrm{MHz}, \mathrm{CDCl}_{3}\right): \delta 0.85\left(3 \mathrm{H}, \mathrm{s}, \mathrm{CH}_{3}\right), 0.86\left(3 \mathrm{H}, \mathrm{s}, \mathrm{CH}_{3}\right)$, $0.87\left(3 \mathrm{H}, \mathrm{s}, \mathrm{CH}_{3}\right), 0.99\left(3 \mathrm{H}, \mathrm{s}, \mathrm{CH}_{3}\right), 1.06\left(3 \mathrm{H}, \mathrm{s}, \mathrm{CH}_{3}\right)$, $1.71\left(3 \mathrm{H}, \mathrm{s}, \mathrm{CH}_{3}\right), 2.06\left(3 \mathrm{H}, \mathrm{s}, \mathrm{COCH}_{3}\right), 2.51(1 \mathrm{H}, \mathrm{m}, \mathrm{H}-$ 19), $4.13(1 \mathrm{H}, \mathrm{d}, J=10.8 \mathrm{~Hz}, \mathrm{H}-28), 4.49(1 \mathrm{H}, \mathrm{m}, \mathrm{H}-3)$, $4.55(1 \mathrm{H}, \mathrm{d}, J=10.8 \mathrm{~Hz}, \mathrm{H}-28), 4.62(1 \mathrm{H}, \mathrm{s}, \mathrm{H}-29), 4.72$ $(1 \mathrm{H}, \mathrm{s}, \mathrm{H}-29), 5.60\left(2 \mathrm{H}, \mathrm{s}, \mathrm{CH}_{2}\right), 7.31-7.33\left(2 \mathrm{H}, \mathrm{m}, \mathrm{H}_{\mathrm{Ar}}\right)$, 7.41-7.44 $\left(3 \mathrm{H}, \mathrm{m}, \mathrm{H}_{\mathrm{Ar}}\right), 7.97(1 \mathrm{H}, \mathrm{s}, \mathrm{CH}$-triazole $) ;{ }^{13} \mathrm{C}$ NMR $\left(150 \mathrm{MHz}, \mathrm{CDCl}_{3}\right): \delta 14.2,14.7,16.0,16.2,16.5$, $18.2,19.1,20.8,21.1,21.3,23.7,25.2,27.1,27.9,29.6$, $29.8,34.1,34.7,37.1,37.7,38.4,40.9,42.7,46.7,47.7$, $48.9,50.3,54.5,55.4,60.4,63.6,80.9,109.9,127.1,128.2$, $129.2,129.3,133.8,140.6,150.1,161.2,171.1$; HRAPCIMS $m / z$ (neg): $668.4474 \mathrm{C}_{42} \mathrm{H}_{58} \mathrm{~N}_{3} \mathrm{O}_{4}$ (calcd. 668.4427).

\section{3-Acetyl-28-[1-(4-fluorobenzyl)-1H-1,2,3-triazol-4-yl]carbo-} nylbetulin (5b) Yield 63\%; m.p. $113-116^{\circ} \mathrm{C}$; IR (KBr) $\nu_{\max } 3138,2963,1734,1539,1457,1226-1193,802 \mathrm{~cm}^{-1}$; ${ }^{1} \mathrm{H}$ NMR $\left(600 \mathrm{MHz}, \mathrm{CDCl}_{3}\right): \delta 0.85\left(3 \mathrm{H}, \mathrm{s}, \mathrm{CH}_{3}\right), 0.86(3 \mathrm{H}$, $\left.\mathrm{s}, \mathrm{CH}_{3}\right), 0.87\left(3 \mathrm{H}, \mathrm{s}, \mathrm{CH}_{3}\right), 1.00\left(3 \mathrm{H}, \mathrm{s}, \mathrm{CH}_{3}\right), 1.06(3 \mathrm{H}, \mathrm{s}$, $\left.\mathrm{CH}_{3}\right), 1.69\left(3 \mathrm{H}, \mathrm{s}, \mathrm{CH}_{3}\right), 2.07\left(3 \mathrm{H}, \mathrm{s}, \mathrm{COCH}_{3}\right), 2.52(1 \mathrm{H}, \mathrm{m}$, $\mathrm{H}-19), 4.14(1 \mathrm{H}, \mathrm{d}, J=10.8 \mathrm{~Hz}, \mathrm{H}-28), 4.49(1 \mathrm{H}, \mathrm{m}, \mathrm{H}-3)$, $4.57(1 \mathrm{H}, \mathrm{d}, J=10.8 \mathrm{~Hz}, \mathrm{H}-28), 4.62(1 \mathrm{H}, \mathrm{s}, \mathrm{H}-29), 4.72$ $(1 \mathrm{H}, \mathrm{s}, \mathrm{H}-29), 5.57\left(2 \mathrm{H}, \mathrm{s}, \mathrm{CH}_{2}\right), 7.10-7.13\left(2 \mathrm{H}, \mathrm{m}, \mathrm{H}_{\mathrm{Ar}}\right)$, 7.31-7.33 $\left(2 \mathrm{H}, \mathrm{m}, \mathrm{H}_{\mathrm{Ar}}\right), 7.97(1 \mathrm{H}, \mathrm{s}, \mathrm{CH}$-triazole $) ;{ }^{13} \mathrm{C}$ NMR $\left(150 \mathrm{MHz}, \mathrm{CDCl}_{3}\right): \delta 13.7,15.1,15.2,15.5,17.1$, $18.1,19.8,20.3,22.7,24.1,26.1,26.9,28.6,28.8,33.1$, $33.7,36.0,36.6,36.8,37.4,39.9,41.7,45.6,46.7,47.8$, 49.3, 52.7, 54.4, 62.6, 79.9, 108.9, 115.3, 115.4, 125.9, $129.1,129.2,139.7,149.0,160.0,161.2,170.0$; HRAPCIMS $m / z$ (neg): $686.4357 \mathrm{C}_{42} \mathrm{H}_{57} \mathrm{FN}_{3} \mathrm{O}_{4}$ (calcd. 686.4333).
3-Acetyl-28-[1-(4-cyanobenzyl)-1H-1,2,3-triazol-4-yl]carbonylbetulin (5c) Yield 56\%; m.p. $137-140{ }^{\circ} \mathrm{C}$; IR (KBr) $\nu_{\max } 3144,2949,2231,1734,1540,1457,1248-1192 \mathrm{~cm}$ ${ }^{-1}$; ${ }^{1} \mathrm{H}$ NMR $\left(600 \mathrm{MHz}, \mathrm{CDCl}_{3}\right): \delta 0.83\left(3 \mathrm{H}, \mathrm{s}, \mathrm{CH}_{3}\right), 0.86$ $\left(3 \mathrm{H}, \mathrm{s}, \mathrm{CH}_{3}\right), 0.87\left(3 \mathrm{H}, \mathrm{s}, \mathrm{CH}_{3}\right), 1.00\left(3 \mathrm{H}, \mathrm{s}, \mathrm{CH}_{3}\right), 1.07$ $\left(3 \mathrm{H}, \mathrm{s}, \mathrm{CH}_{3}\right), 1.70\left(3 \mathrm{H}, \mathrm{s}, \mathrm{CH}_{3}\right), 2.07\left(3 \mathrm{H}, \mathrm{s}, \mathrm{COCH}_{3}\right), 2.52$ $(1 \mathrm{H}, \mathrm{m}, \mathrm{H}-19), 4.16(1 \mathrm{H}, \mathrm{d}, J=10.8 \mathrm{~Hz}, \mathrm{H}-28), 4.49(1 \mathrm{H}$, $\mathrm{m}, \mathrm{H}-3), 4.58(1 \mathrm{H}, \mathrm{d}, J=10.8 \mathrm{~Hz}, \mathrm{H}-28), 4.63(1 \mathrm{H}, \mathrm{s}, \mathrm{H}-$ 29), $4.72(1 \mathrm{H}, \mathrm{s}, \mathrm{H}-29), 5.68\left(2 \mathrm{H}, \mathrm{s}, \mathrm{CH}_{2}\right), 7.40(2 \mathrm{H}, \mathrm{d}, J=$ $\left.8.4 \mathrm{~Hz}, \mathrm{H}_{\mathrm{Ar}}\right), 7.72\left(2 \mathrm{H}, \mathrm{d}, J=8.4 \mathrm{~Hz}, \mathrm{H}_{\mathrm{Ar}}\right), 8.04(1 \mathrm{H}, \mathrm{s}$, $\mathrm{CH}$-triazole); ${ }^{13} \mathrm{C}$ NMR $\left(150 \mathrm{MHz}, \mathrm{CDCl}_{3}\right): \delta 14.8,16.0$, $16.2,16.5,18.2,19.1,19.3,20.8,21.3,23.7,25.2,27.1$, $27.9,29.6,29.8,34.1,34.7,37.1,37.7,37.8,38.4,40.9$, $42.7,46.7,47.7,48.9,50.3,53.7,55.4,63.8,80.9,110.3$, $113.3,117.9,124.4,127.3,128.5,133.1,138.9,141.0$, 150.0, 160.9, 171.0; HRAPCIMS $\mathrm{m} / \mathrm{z}$ (neg): 693.4352 $\mathrm{C}_{43} \mathrm{H}_{57} \mathrm{~N}_{4} \mathrm{O}_{4}$ (calcd. 693.4380).

3-Acetyl-28-(1-phenylthiomethyl-1 H-1,2,3-triazol-4-yl)carbonylbetulin (5d) Yield $60 \%$; m.p. $105-107^{\circ} \mathrm{C}$; IR (KBr) $\nu_{\max } 2945,1734,1539,1456,1247-1194 \mathrm{~cm}^{-1} ;{ }^{1} \mathrm{H}$ NMR $\left(600 \mathrm{MHz}, \mathrm{CDCl}_{3}\right): \delta 0.86\left(3 \mathrm{H}, \mathrm{s}, \mathrm{CH}_{3}\right), 0.87\left(3 \mathrm{H}, \mathrm{s}, \mathrm{CH}_{3}\right)$, $0.88\left(3 \mathrm{H}, \mathrm{s}, \mathrm{CH}_{3}\right), 1.01\left(3 \mathrm{H}, \mathrm{s}, \mathrm{CH}_{3}\right), 1.09\left(3 \mathrm{H}, \mathrm{s}, \mathrm{CH}_{3}\right)$, $1.71\left(3 \mathrm{H}, \mathrm{s}, \mathrm{CH}_{3}\right), 2.07\left(3 \mathrm{H}, \mathrm{s}, \mathrm{COCH}_{3}\right), 2.51(1 \mathrm{H}, \mathrm{m}, \mathrm{H}-$ 19), $4.14(1 \mathrm{H}, \mathrm{d}, J=10.8 \mathrm{~Hz}, \mathrm{H}-28), 4.49(1 \mathrm{H}, \mathrm{m}, \mathrm{H}-3)$, $4.55(1 \mathrm{H}, \mathrm{d}, J=10.8 \mathrm{~Hz}, \mathrm{H}-28), 4.63(1 \mathrm{H}, \mathrm{s}, \mathrm{H}-29), 4.73$ $(1 \mathrm{H}, \mathrm{s}, \mathrm{H}-29), 5.68\left(2 \mathrm{H}, \mathrm{s}, \mathrm{CH}_{2}\right), 7.35-7.36\left(5 \mathrm{H}, \mathrm{m}, \mathrm{H}_{\mathrm{Ar}}\right)$, $8.04\left(1 \mathrm{H}, \mathrm{s}, \mathrm{CH}\right.$-triazole); ${ }^{13} \mathrm{C} \mathrm{NMR}\left(150 \mathrm{MHz}, \mathrm{CDCl}_{3}\right): \delta$ $14.8,16.1,16.2,16.5,18.2,19.1,20.8,21.3,23.7,25.2$, 25.6, 27.1, 27.9, 29.6, 29.8, 34.1, 34.7, 37.1, 37.7, 37.8, $38.4,40.9,42.7,46.7,47.8,48.9,50.3,54.3,55.4,63.6$, 68.0, 80.9, 110.0, 126.8, 129.1, 129.7, 131.3, 132.4, 140.6, 150.0, 160.9, 171.0; HRAPCIMS $\mathrm{m} / z$ (neg): 700.4141 $\mathrm{C}_{42} \mathrm{H}_{58} \mathrm{~N}_{3} \mathrm{O}_{4} \mathrm{~S}$ (calcd. 700.4148).

3-Acetyl-28-[1-(3'-deoxythymidine-5'-yl)-1H-1,2,3-triazol-4yl]carbonylbetulin (5e) Yield 65\%; m.p. $204-207^{\circ} \mathrm{C}$; IR $(\mathrm{KBr}) \nu_{\max } 3446,3068,2945,1730,1541,1456$, $1246-1192 \mathrm{~cm}^{-1} ;{ }^{1} \mathrm{H}$ NMR $\left(600 \mathrm{MHz}\right.$, DMSO-d $\left.{ }_{6}\right): \delta 0.81$ $\left(3 \mathrm{H}, \mathrm{s}, \mathrm{CH}_{3}\right), 0.83\left(3 \mathrm{H}, \mathrm{s}, \mathrm{CH}_{3}\right), 0.98\left(3 \mathrm{H}, \mathrm{s}, \mathrm{CH}_{3}\right), 1.02$ $\left(3 \mathrm{H}, \mathrm{s}, \mathrm{CH}_{3}\right), 1.18\left(3 \mathrm{H}, \mathrm{s}, \mathrm{CH}_{3}\right), 1.67\left(3 \mathrm{H}, \mathrm{s}, \mathrm{CH}_{3}\right), 1.78$ $\left(3 \mathrm{H}, \mathrm{s}, \mathrm{CH}_{3}-\mathrm{AZT}\right), 2.03\left(3 \mathrm{H}, \mathrm{s}, \mathrm{COCH}_{3}\right), 2.55(1 \mathrm{H}, \mathrm{m}$, AZT), 2.67 (1H, m, H-19), 3.65-3.70 (2H, m, AZT), 4.03 $(1 \mathrm{H}, \mathrm{d}, J=10.8 \mathrm{~Hz}, \mathrm{H}-28), 4.27(1 \mathrm{H}, \mathrm{t}, J=4.8 \mathrm{~Hz}, \mathrm{AZT})$, $4.38(1 \mathrm{H}, \mathrm{m}, \mathrm{H}-3), 4.55(1 \mathrm{H}, \mathrm{d}, J=10.8 \mathrm{~Hz}, \mathrm{H}-28), 4.59$ $(1 \mathrm{H}, \mathrm{s}, \mathrm{H}-29), 4.73(1 \mathrm{H}, \mathrm{s}, \mathrm{H}-29), 5.28(1 \mathrm{H}, \mathrm{t}, J=4.8 \mathrm{~Hz}$, AZT), $5.46(1 \mathrm{H}, \mathrm{m}, \mathrm{AZT}), 6.44(1 \mathrm{H}, \mathrm{t}, J=6.6 \mathrm{~Hz}, \mathrm{AZT})$, $7.82(1 \mathrm{H}, \mathrm{s}, \mathrm{AZT}), 8.32(1 \mathrm{H}, \mathrm{s}, \mathrm{CH}$-triazole $), 9.01(1 \mathrm{H}, \mathrm{s}$, NH-AZT); ${ }^{13} \mathrm{C}$ NMR $\left(150 \mathrm{MHz}\right.$, DMSO-d $\left.\mathrm{d}_{6}\right): \delta 12.7,14.9$, $15.9,16.1,16.3,16.9,18.2,19.3,20.8,21.5,23.8,25.3$, $27.1,28.1,29.4,29.7,34.0,34.6,37.1,37.6,37.7,37.8$, $38.2,42.8,46.8,47.5,48.7,49.9,55.0,55.6,60.2,61.1$, $62.7,79.6,80.4,84.6,110.1,110.5,129.3,136.7,139.3$, 
$150.9, \quad 160.9,164.2 ; 170.6 ;$ HRAPCIMS $\mathrm{m} / \mathrm{z}$ (neg): 802.4768 $\mathrm{C}_{45} \mathrm{H}_{64} \mathrm{~N}_{5} \mathrm{O}_{8}$ (calcd. 802.4755).

\section{3-Acetyl-28-[1-(1-deoxy- $\beta$-D-glucopyranosyl)-1H-1,2,3-tria-} zol-4-yl]carbonylbetulin (5f) Yield $82 \%$; m.p. $210-212{ }^{\circ} \mathrm{C}$; IR (KBr) $\nu_{\max } 3419, \quad 2943,1732,1543,1456$, $1246-1191 \mathrm{~cm}^{-1} ;{ }^{1} \mathrm{H}$ NMR (600 MHz, DMSO-d $\left.{ }_{6}\right): \delta 0.80$ $\left(3 \mathrm{H}, \mathrm{s}, \mathrm{CH}_{3}\right), 0.81\left(3 \mathrm{H}, \mathrm{s}, \mathrm{CH}_{3}\right), 0.83\left(3 \mathrm{H}, \mathrm{s}, \mathrm{CH}_{3}\right), 0.98$ $\left(3 \mathrm{H}, \mathrm{s}, \mathrm{CH}_{3}\right), 1.04\left(3 \mathrm{H}, \mathrm{s}, \mathrm{CH}_{3}\right), 1.68\left(3 \mathrm{H}, \mathrm{s}, \mathrm{CH}_{3}\right), 1.85$ $(1 \mathrm{H}, \mathrm{m}, \mathrm{OH}), 2.00\left(3 \mathrm{H}, \mathrm{s}, \mathrm{COCH}_{3}\right), 2.54(1 \mathrm{H}, \mathrm{m}, \mathrm{H}-19)$, $3.27(1 \mathrm{H}, \mathrm{m}, \mathrm{OH}), 3.39(1 \mathrm{H}, \mathrm{m}, \mathrm{OH}), 3.44(1 \mathrm{H}, \mathrm{m}, \mathrm{OH})$, $3.71(1 \mathrm{H}, \mathrm{m}, \mathrm{CH}$-sugar), $3.85(1 \mathrm{H}, \mathrm{m}, \mathrm{CH}$-sugar $), 4.03(1 \mathrm{H}$, $\mathrm{d}, J=10.8 \mathrm{~Hz}, \mathrm{H}-28), 4.37(1 \mathrm{H}, \mathrm{m}, \mathrm{H}-3), 4.55(1 \mathrm{H}, \mathrm{d}, J=$ $10.8 \mathrm{~Hz}, \mathrm{H}-28), 4.59$ (1H, s, H-29), 4.63 (1H, m, CH-sugar), $4.73(1 \mathrm{H}, \mathrm{s}, \mathrm{H}-29), 5.20(1 \mathrm{H}, \mathrm{d}, J=5.4 \mathrm{~Hz}, \mathrm{CH}$-sugar), 5.35 $(1 \mathrm{H}, \mathrm{d}, J=5.4 \mathrm{~Hz}, \mathrm{CH}$-sugar $), 5.46(1 \mathrm{H}, \mathrm{d}, J=5.4 \mathrm{~Hz}, \mathrm{CH}-$ sugar), $5.61(1 \mathrm{H}, \mathrm{d}, J=5.4 \mathrm{~Hz}, \mathrm{CH}$-sugar $), 9.08(1 \mathrm{H}, \mathrm{s}$, CH-triazole); ${ }^{13} \mathrm{C}$ NMR $\left(150 \mathrm{MHz}\right.$, DMSO-d $\left.\mathrm{d}_{6}\right): \delta 15.0$, $16.1,16.3,16.9,18.2,19.3,20.8,21.5,23.8,25.2,27.1$, $28.1,29.4,29.6,34.0,34.6,37.1,37.6,37.8,38.2,39.6$, $42.8,46.8,47.5,48.7,50.0,55.0,61.2,62.6,69.9,72.4$, 77.2, 79.6, 80.6, 88.3, 110.5, 129.1, 139.2, 150.3, 160.9, 170.6; HRAPCIMS $m / z$ (neg): $740.4480 \quad \mathrm{C}_{41} \mathrm{H}_{62} \mathrm{~N}_{3} \mathrm{O}_{9}$ (calcd. 740.4486).

\section{3-Acetyl-28-(1-ethylacetyl-1H-1,2,3-triazol-4-yl)carbonylbe-} tulin (5g) Yield $80 \%$; m.p. $221-224^{\circ} \mathrm{C}$; IR $(\mathrm{KBr}) \nu_{\max }$ 2945, 1732, 1544, 1465, 1247-1213 $\mathrm{cm}^{-1} ;{ }^{1} \mathrm{H}$ NMR $\left(600 \mathrm{MHz}, \mathrm{CDCl}_{3}\right): \delta 0.85\left(3 \mathrm{H}, \mathrm{s}, \mathrm{CH}_{3}\right), 0.86\left(3 \mathrm{H}, \mathrm{s}, \mathrm{CH}_{3}\right)$, $0.88\left(3 \mathrm{H}, \mathrm{s}, \mathrm{CH}_{3}\right), 0.99\left(3 \mathrm{H}, \mathrm{s}, \mathrm{CH}_{3}\right), 1.08\left(3 \mathrm{H}, \mathrm{s}, \mathrm{CH}_{3}\right)$, $1.34\left(3 \mathrm{H}, \mathrm{t}, J=7.2 \mathrm{~Hz}, \mathrm{CH}_{3}\right), 1.68\left(3 \mathrm{H}, \mathrm{s}, \mathrm{CH}_{3}\right), 2.07(3 \mathrm{H}$, s, $\left.\mathrm{COCH}_{3}\right), 2.53(1 \mathrm{H}, \mathrm{m}, \mathrm{H}-19), 4.18(1 \mathrm{H}, \mathrm{d}, J=10.8 \mathrm{~Hz}$, $\mathrm{H}-28), 4.32\left(2 \mathrm{H}, \mathrm{q}, J=7.2 \mathrm{~Hz}, \mathrm{OCH}_{2}\right), 4.48(1 \mathrm{H}, \mathrm{m}, \mathrm{H}-3)$, $4.58(1 \mathrm{H}, \mathrm{d}, J=10.8 \mathrm{~Hz}, \mathrm{H}-28), 4.63(1 \mathrm{H}, \mathrm{s}, \mathrm{H}-29), 4.73$ $(1 \mathrm{H}, \mathrm{s}, \mathrm{H}-29), 5.24\left(2 \mathrm{H}, \mathrm{s}, \mathrm{CH}_{2}\right), 8.24(1 \mathrm{H}, \mathrm{s}, \mathrm{CH}$-triazole); ${ }^{13} \mathrm{C} \mathrm{NMR}\left(150 \mathrm{MHz}, \mathrm{CDCl}_{3}\right): \delta 14.1,14.8,16.1,16.2,16.5$, 18.2, 20.8, 21.3, 23.7, 25.2, 27.1, 27.9, 29.6, 29.8, 34.1, $34.7,37.1,37.7,37.8,38.4,40.9,42.7,46.7,47.8,48.9$, $50.3,51.0,55.4,62.8,63.7,80.9,110.0,128.7,140.7$, $150.1,160.9,165.7,171.1$; HRAPCIMS $\mathrm{m} / \mathrm{z}$ (neg): $664.4329 \mathrm{C}_{39} \mathrm{H}_{58} \mathrm{~N}_{3} \mathrm{O}_{6}$ (calcd. 664.4326).

\section{3-Acetyl-28-[1-(3-hydroxypropyl)-1H-1,2,3-triazol-4-yl]car-} bonylbetulin (5h) Yield 83\%; m.p. 116-119 ${ }^{\circ} \mathrm{C}$; IR (KBr) $\nu_{\max } 3425,2945,1732,1543,1465,1246-1199 \mathrm{~cm}^{-1} ;{ }^{1} \mathrm{H}$ NMR $\left(600 \mathrm{MHz}, \mathrm{DMSO}-\mathrm{d}_{6}\right): \delta 0.80\left(3 \mathrm{H}, \mathrm{s}, \mathrm{CH}_{3}\right), 0.81(3 \mathrm{H}$, $\left.\mathrm{s}, \mathrm{CH}_{3}\right), 0.82\left(3 \mathrm{H}, \mathrm{s}, \mathrm{CH}_{3}\right), 0.98\left(3 \mathrm{H}, \mathrm{s}, \mathrm{CH}_{3}\right), 1.03(3 \mathrm{H}, \mathrm{s}$, $\left.\mathrm{CH}_{3}\right), 1.09\left(2 \mathrm{H}, \mathrm{m}, \mathrm{CH}_{2}\right), 1.67\left(3 \mathrm{H}, \mathrm{s}, \mathrm{CH}_{3}\right), 2.02(3 \mathrm{H}, \mathrm{s}$, $\left.\mathrm{COCH}_{3}\right), 2.51(1 \mathrm{H}, \mathrm{m}, \mathrm{H}-19), 3.34\left(2 \mathrm{H}, \mathrm{m}, \mathrm{CH}_{2}\right), 4.01(1 \mathrm{H}$, d, $J=10.8 \mathrm{~Hz}, \mathrm{H}-28), 4.38(1 \mathrm{H}, \mathrm{m}, \mathrm{H}-3), 4.48(2 \mathrm{H}, \mathrm{t}, J=$ $\left.7.2 \mathrm{~Hz}, \mathrm{CH}_{2}\right), 4.54(1 \mathrm{H}, \mathrm{d}, J=10.8 \mathrm{~Hz}, \mathrm{H}-28), 4.59(1 \mathrm{H}, \mathrm{s}$, $\mathrm{H}-29), 4.73(1 \mathrm{H}, \mathrm{s}, \mathrm{H}-29), 8.81$ (1H, s, CH-triazole); ${ }^{13} \mathrm{C}$ NMR (150 MHz, DMSO-d $\left.\mathrm{d}_{6}\right): \delta 14.9,16.1,16.3,16.9,18.2$,
$19.2,20.7,21.5,24.8,25.1,27.1,28.1,29.4,29.6,33.1$, $34.0,34.6,37.1,37.6,37.8,38.2,40.9,42.8,46.8,47.5$, 47.6, 48.7, 50.0, 55.0, 57.8, 62.5, 80.4, 110.4, 129.7, 139.0, 150.3, 161.0, 170.6; HRAPCIMS $\mathrm{m} / \mathrm{z}$ (neg): 636.4363 $\mathrm{C}_{38} \mathrm{H}_{58} \mathrm{~N}_{3} \mathrm{O}_{5}$ (calcd. 636.4376).

2-Amino-3-[4-(3-acetyl-28-betulinylcarbonyl)-1H-1,2,3-triazol-1-yl]propanoic acid (5i) Yield 45\%; oil; IR (KBr) $\nu_{\max }$ 3444, 2956, 1732, 1602, 1458, 1246-1122 $\mathrm{cm}^{-1}$; ${ }^{1} \mathrm{H}$ NMR $\left(600 \mathrm{MHz}, \mathrm{DMSO}_{-} \mathrm{d}_{6}\right) \delta: 0.80\left(3 \mathrm{H}, \mathrm{s}, \mathrm{CH}_{3}\right), 0.82(3 \mathrm{H}, \mathrm{s}$, $\left.\mathrm{CH}_{3}\right), 0.86\left(3 \mathrm{H}, \mathrm{s}, \mathrm{CH}_{3}\right), 0.92\left(3 \mathrm{H}, \mathrm{s}, \mathrm{CH}_{3}\right), 1.01(3 \mathrm{H}, \mathrm{s}$, $\left.\mathrm{CH}_{3}\right), 1.06(1 \mathrm{H}, \mathrm{t}, J=7.2 \mathrm{~Hz}, \mathrm{CH}), 1.67\left(3 \mathrm{H}, \mathrm{s}, \mathrm{CH}_{3}\right), 2.00$ $\left(3 \mathrm{H}, \mathrm{s}, \mathrm{COCH}_{3}\right), 2.52(1 \mathrm{H}, \mathrm{m}, \mathrm{H}-19), 4.14(1 \mathrm{H}, \mathrm{d}, J=$ $10.8 \mathrm{~Hz}, \mathrm{H}-28), 4.23\left(2 \mathrm{H}, \mathrm{d}, J=7.2 \mathrm{~Hz}, \mathrm{CH}_{2}\right), 4.37(1 \mathrm{H}, \mathrm{m}$, $\mathrm{H}-3), 4.55(1 \mathrm{H}, \mathrm{d}, J=10.8 \mathrm{~Hz}, \mathrm{H}-28), 4.58(1 \mathrm{H}, \mathrm{s}, \mathrm{H}-29)$, $4.73(1 \mathrm{H}, \mathrm{s}, \mathrm{H}-29), 8.62(1 \mathrm{H}, \mathrm{s}, \mathrm{CH}$-triazole $) ;{ }^{13} \mathrm{C}$ NMR $\left(150 \mathrm{MHz}, \mathrm{DMSO}-\mathrm{d}_{6}\right): \delta 14.9,15.8,16.1,16.8,18.3,19.2$, $19.6,21.2,22.9,23.7,26.8,28.8,30.3,30.6,30.8,34.1$, $34.5,36.8,37.2,37.5,38.5,39.6,42.8,46.2,47.0,47.2$, $48.6,50.1,54.3,56.5,67.8,80.2,110.0,129.2,132.1$, 150.1, 161.0, 167.5; HRAPCIMS $\mathrm{m} / \mathrm{z}$ (neg): 665.4269 $\mathrm{C}_{38} \mathrm{H}_{57} \mathrm{~N}_{4} \mathrm{O}_{6}$ (calcd. 665.4278).

\section{8-(1-Benzyl-1H-1,2,3-triazol-4-yl)carbonylbetulone (6a)} Yield $81 \%$; m.p. $196-198^{\circ} \mathrm{C}$; IR (KBr) $\nu_{\max } 2963,1738$, $1700,1539,1465,1261-1193 \mathrm{~cm}^{-1}$; ${ }^{1} \mathrm{H}$ NMR $(600 \mathrm{MHz}$, $\left.\mathrm{CDCl}_{3}\right) \delta: 0.94\left(3 \mathrm{H}, \mathrm{s}, \mathrm{CH}_{3}\right), 1.02\left(3 \mathrm{H}, \mathrm{s}, \mathrm{CH}_{3}\right), 1.05(3 \mathrm{H}, \mathrm{s}$, $\left.\mathrm{CH}_{3}\right), 1.10\left(3 \mathrm{H}, \mathrm{s}, \mathrm{CH}_{3}\right), 1.12\left(3 \mathrm{H}, \mathrm{s}, \mathrm{CH}_{3}\right), 1.69(3 \mathrm{H}, \mathrm{s}$, $\left.\mathrm{CH}_{3}\right), 2.52(1 \mathrm{H}, \mathrm{m}, \mathrm{H}-19), 4.15(1 \mathrm{H}, \mathrm{d}, J=10.8 \mathrm{~Hz}, \mathrm{H}-28)$, $4.57(1 \mathrm{H}, \mathrm{d}, J=10.8 \mathrm{~Hz}, \mathrm{H}-28), 4.62(1 \mathrm{H}, \mathrm{s}, \mathrm{H}-29), 4.72$ $(1 \mathrm{H}, \mathrm{s}, \mathrm{H}-29), 5.60\left(2 \mathrm{H}, \mathrm{s}, \mathrm{CH}_{2}\right), 7.31-7.33\left(2 \mathrm{H}, \mathrm{m}, \mathrm{H}_{\mathrm{Ar}}\right)$, 7.41-7.44 (3H, m, $\left.\mathrm{H}_{\mathrm{Ar}}\right), 7.97$ (1H, s, CH-triazole) ${ }^{13} \mathrm{C} \mathrm{NMR}$ $\left(150 \mathrm{MHz}, \mathrm{CDCl}_{3}\right): \delta 14.7,15.8,15.9,19.1,19.6,21.1$, $21.3,25.2,25.6,26.6,27.1,29.6,29.8,33.5,34.2,34.7$, $36.9,37.8,39.6,40.9,42.8,46.7,47.4,47.7,48.8,49.7$, $54.5,55.0,63.5,68.0,110.0,127.1,128.2,129.2,129.3$, 133.8, 140.6, 150.0, 161.2, 218.0; HRAPCIMS $\mathrm{m} / \mathrm{z}$ (neg): 624.4171 $\mathrm{C}_{40} \mathrm{H}_{54} \mathrm{~N}_{3} \mathrm{O}_{3}$ (calcd. 624.4165).

28-[1-(4-Fluorobenzyl)-1H-1,2,3-triazol-4-yl]carbonylbetulone (6b) Yield $73 \%$; m.p. $220-223{ }^{\circ} \mathrm{C}$; IR (KBr) $\nu_{\max }$ $3131,2957,1742,1699,1539,1456,1223-1198,814 \mathrm{~cm}$ ${ }^{-1}$; ${ }^{1} \mathrm{H}$ NMR $\left(600 \mathrm{MHz}, \mathrm{CDCl}_{3}\right): \delta 0.86\left(3 \mathrm{H}, \mathrm{s}, \mathrm{CH}_{3}\right), 0.91$ $\left(3 \mathrm{H}, \mathrm{s}, \mathrm{CH}_{3}\right), 0.92\left(3 \mathrm{H}, \mathrm{s}, \mathrm{CH}_{3}\right), 0.95\left(3 \mathrm{H}, \mathrm{s}, \mathrm{CH}_{3}\right), 1.02$ $\left(3 \mathrm{H}, \mathrm{s}, \mathrm{CH}_{3}\right), 1.68\left(3 \mathrm{H}, \mathrm{s}, \mathrm{CH}_{3}\right), 2.43(1 \mathrm{H}, \mathrm{m}, \mathrm{H}-19), 4.05$ $(1 \mathrm{H}, \mathrm{d}, J=10.8 \mathrm{~Hz}, \mathrm{H}-28), 4.48(1 \mathrm{H}, \mathrm{d}, J=10.8 \mathrm{~Hz}, \mathrm{H}-28)$, $4.53(1 \mathrm{H}, \mathrm{s}, \mathrm{H}-29), 4.63(1 \mathrm{H}, \mathrm{s}, \mathrm{H}-29), 5.48\left(2 \mathrm{H}, \mathrm{s}, \mathrm{CH}_{2}\right)$, 7.01-7.04 $\left(2 \mathrm{H}, \mathrm{m}, \mathrm{H}_{\mathrm{Ar}}\right), 7.23-7.36\left(2 \mathrm{H}, \mathrm{m}, \mathrm{H}_{\mathrm{Ar}}\right), 7.88(1 \mathrm{H}$, s, CH-triazole); ${ }^{13} \mathrm{C}$ NMR $\left(150 \mathrm{MHz}, \mathrm{CDCl}_{3}\right): \delta 14.7,15.8$, $15.9,19.2,19.6,21.1,21.3,25.2,26.6,27.1,29.6,29.8$, $33.5,34.2,34.7,36.9,37.8,39.6,40.9,42.8,46.7,47.4$, $47.7,48.8,49.7,53.7,55.0,63.6,68.1,110.0,116.3,116.5$, 
$126.2,126.3,130.2,140.0,150.0,161.1,218.0$; HRAPCIMS $m / z$ (neg): $642.4063 \mathrm{C}_{40} \mathrm{H}_{53} \mathrm{FN}_{3} \mathrm{O}_{3}$ (calcd. 642.4071).

\section{8-[1-(4-Cyanobenzyl)-1H-1,2,3-triazol-4-yl]carbonylbetu-}

lone (6c) Yield 57\%; m.p. 211-214 ${ }^{\circ} \mathrm{C}$; IR (KBr) $\nu_{\max }$ $3127,2951,2229,1734,1705,1525,1457,1243-1147 \mathrm{~cm}$ ${ }^{-1}$; ${ }^{1} \mathrm{H}$ NMR $\left(600 \mathrm{MHz}, \mathrm{CDCl}_{3}\right): \delta 0.87\left(3 \mathrm{H}, \mathrm{s}, \mathrm{CH}_{3}\right), 0.93$ $\left(3 \mathrm{H}, \mathrm{s}, \mathrm{CH}_{3}\right), 0.96\left(3 \mathrm{H}, \mathrm{s}, \mathrm{CH}_{3}\right), 1.02\left(3 \mathrm{H}, \mathrm{s}, \mathrm{CH}_{3}\right), 1.03$ $\left(3 \mathrm{H}, \mathrm{s}, \mathrm{CH}_{3}\right), 1.68\left(3 \mathrm{H}, \mathrm{s}, \mathrm{CH}_{3}\right), 2.44(1 \mathrm{H}, \mathrm{m}, \mathrm{H}-19), 4.07$ $(1 \mathrm{H}, \mathrm{d}, J=10.8 \mathrm{~Hz}, \mathrm{H}-28), 4.49(1 \mathrm{H}, \mathrm{d}, J=10.8 \mathrm{~Hz}, 1 \mathrm{H}$, $\mathrm{H}-28), 4.54(1 \mathrm{H}, \mathrm{s}, \mathrm{H}-29), 4.63$ (1H, s, H-29), 5.59 (2H, s, $\left.\mathrm{CH}_{2}\right), 7.31\left(2 \mathrm{H}, \mathrm{d}, J=8.4 \mathrm{~Hz}, \mathrm{H}_{\mathrm{Ar}}\right), 7.63(2 \mathrm{H}, \mathrm{d}, J=$ $\left.8.4 \mathrm{~Hz}, \mathrm{H}_{\mathrm{Ar}}\right), 7.96(1 \mathrm{H}, \quad \mathrm{s}, \quad \mathrm{CH}$-triazole $) ;{ }^{13} \mathrm{C} \quad \mathrm{NMR}$ $\left(150 \mathrm{MHz}, \mathrm{CDCl}_{3}\right): \delta 14.7,15.8,15.9,19.1,19.6,21.1$, $21.3,23.7,25.2,26.6,27.1,29.6,29.8,33.5,34.2,34.7$, $36.9,37.8,39.6,40.9,42.8,46.7,47.4,47.7,48.8,49.7$, 53.7, 55.0, 63.7 110.1, 113.3, 117.9, 127.4, 128.5, 133.1, $138.9,141.0,149.9,160.9,218.1$; HRAPCIMS $\mathrm{m} / \mathrm{z}$ (neg): $649.4095 \mathrm{C}_{41} \mathrm{H}_{53} \mathrm{~N}_{4} \mathrm{O}_{3}$ (calcd. 649.4118).

\section{8-(1-Phenylthiomethyl-1H-1,2,3-triazol-4-yl)carbonylbetu-} Ione (6d) Yield $87 \%$; m.p. $188-191{ }^{\circ} \mathrm{C}$; IR (KBr) $\nu_{\max }$ $3132,2960,1734,1705,1521,1456,1241-1196 \mathrm{~cm}^{-1} ;{ }^{1} \mathrm{H}$ NMR $\left(600 \mathrm{MHz}, \mathrm{CDCl}_{3}\right): \delta 0.96\left(3 \mathrm{H}, \mathrm{s}, \mathrm{CH}_{3}\right), 1.03(3 \mathrm{H}, \mathrm{s}$, $\left.\mathrm{CH}_{3}\right), 1.05\left(3 \mathrm{H}, \mathrm{s}, \mathrm{CH}_{3}\right), 1.09\left(3 \mathrm{H}, \mathrm{s}, \mathrm{CH}_{3}\right), 1.11(3 \mathrm{H}, \mathrm{s}$, $\left.\mathrm{CH}_{3}\right), 1.69\left(3 \mathrm{H}, \mathrm{s}, \mathrm{CH}_{3}\right), 2.53(1 \mathrm{H}, \mathrm{m}, \mathrm{H}-19), 4.15(1 \mathrm{H}, \mathrm{d}, J$ $=10.8 \mathrm{~Hz}, \mathrm{H}-28), 4.57(1 \mathrm{H}, \mathrm{d}, J=10.8 \mathrm{~Hz}, \mathrm{H}-28), 4.63$ $(1 \mathrm{H}, \mathrm{s}, \mathrm{H}-29), 4.74(1 \mathrm{H}, \mathrm{s}, \mathrm{H}-29), 5.69\left(2 \mathrm{H}, \mathrm{s}, \mathrm{CH}_{2}\right), 7.34-$ $7.37\left(5 \mathrm{H}, \mathrm{m}, \mathrm{H}_{\mathrm{Ar}}\right), 8.06(1 \mathrm{H}, \mathrm{s}, \mathrm{CH}-$ triazole $) ;{ }^{13} \mathrm{C}$ NMR $\left(150 \mathrm{MHz}, \mathrm{CDCl}_{3}\right): \delta 14.7,15.8,15.9,19.1,19.6,21.1$, $21.3,25.2,25.6,26.6,27.1,29.6,29.8,33.5,34.2,34.7$, $36.9,37.8,39.6,40.9,42.8,46.7,47.4,47.7,48.8,49.7$, 54.3, 55.0, 63.6, 68.0, 110.0, 126.8, 129.1, 129.7, 131.3, 132.4, 150.0, 160.9, 218.1; HRAPCIMS $\mathrm{m} / \mathrm{z}$ (neg): 656.3895 $\mathrm{C}_{40} \mathrm{H}_{54} \mathrm{~N}_{3} \mathrm{O}_{3} \mathrm{~S}$ (calcd. 656.3886).

28-[1-(3'-Deoxythymidine-5'-yl)-1H-1,2,3-triazol-4-yl]carbonylbetulone (6e) Yield 73\%; m.p. $199-202{ }^{\circ} \mathrm{C}$; IR (KBr) $\nu_{\max } 3447,3068,2945,1729,1697,1541,1458$, $1226-1163 \mathrm{~cm}^{-1} ;{ }^{1} \mathrm{H}$ NMR (600 MHz, DMSO-d 6 ): $\delta 0.88$ $\left(3 \mathrm{H}, \mathrm{s}, \mathrm{CH}_{3}\right), 0.94\left(3 \mathrm{H}, \mathrm{s}, \mathrm{CH}_{3}\right), 0.99\left(3 \mathrm{H}, \mathrm{s}, \mathrm{CH}_{3}\right), 1.02$ $\left(3 \mathrm{H}, \mathrm{s}, \mathrm{CH}_{3}\right), 1.05\left(3 \mathrm{H}, \mathrm{s}, \mathrm{CH}_{3}\right), 1.68\left(3 \mathrm{H}, \mathrm{s}, \mathrm{CH}_{3}\right), 1.74$ $\left(3 \mathrm{H}, \mathrm{s}, \mathrm{CH}_{3}-\mathrm{AZT}\right), 2.51(1 \mathrm{H}, \mathrm{m}, \mathrm{AZT}), 2.67(1 \mathrm{H}, \mathrm{m}, \mathrm{H}-19)$, $3.65-3.70(2 \mathrm{H}, \mathrm{m}, \mathrm{AZT}), 4.04(1 \mathrm{H}, \mathrm{d}, J=10.8 \mathrm{~Hz}, \mathrm{H}-28)$, $4.27(1 \mathrm{H}, \mathrm{t}, J=4.8 \mathrm{~Hz}, \mathrm{AZT}), 4.55(1 \mathrm{H}, \mathrm{d}, J=10.8 \mathrm{~Hz}, \mathrm{H}-$ 28), $4.58(1 \mathrm{H}, \mathrm{s}, \mathrm{H}-29), 4.74$ (1H, s, H-29), 5.27 (1H, t, $J=$ $4.8 \mathrm{~Hz}, \mathrm{AZT}), 5.46(1 \mathrm{H}, \mathrm{m}, \mathrm{AZT}), 6.44(1 \mathrm{H}, \mathrm{t}, J=6.6 \mathrm{~Hz}$, AZT), $7.82(1 \mathrm{H}, \mathrm{s}, \mathrm{AZT}), 8.32(1 \mathrm{H}, \mathrm{s}, \mathrm{CH}$-triazole $), 9.02$ $(1 \mathrm{H}, \mathrm{s}, \mathrm{NH}-\mathrm{AZT}) ;{ }^{13} \mathrm{C}$ NMR $\left(150 \mathrm{MHz}, \mathrm{DMSO}-\mathrm{d}_{6}\right): \delta 12.7$, $14.9,15.8,15.9,16.1,19.3,19.6,21.2,21.3,25.3,26.8$, $27.1,29.4,29.6,33.4,34.1,34.6,36.8,37.6,37.7,39.3$, $39.6,42.8,46.8,47.0,47.5,48.6,49.4,54.3,55.6,60.2$, $61.1,62.7,79.6,84.3,84.7,110.1,110.5,129.3,136.7$,
139.3, 150.3, 150.9, 160.9, 164.2, 217.0; HRAPCIMS $\mathrm{m} / \mathrm{z}$ (neg): $758.4484 \mathrm{C}_{43} \mathrm{H}_{60} \mathrm{~N}_{5} \mathrm{O}_{7}$ (calcd. 758.4493).

28-[1-(1-Deoxy- $\beta$-D-glucopyranosyl)-1 H-1,2,3-triazol-4-yl] carbonylbetulone (6f) Yield $74 \%$; m.p. $187-189^{\circ} \mathrm{C}$; IR $(\mathrm{KBr}) \quad \nu_{\max } \quad 3419, \quad 2939,1732,1701,1541,1458$, $1232-1190 \mathrm{~cm}^{-1} ;{ }^{1} \mathrm{H}$ NMR $\left(600 \mathrm{MHz}, \mathrm{DMSO}-\mathrm{d}_{6}\right): \delta 0.88$ $\left(3 \mathrm{H}, \mathrm{s}, \mathrm{CH}_{3}\right), 0.94\left(3 \mathrm{H}, \mathrm{s}, \mathrm{CH}_{3}\right), 0.99\left(3 \mathrm{H}, \mathrm{s}, \mathrm{CH}_{3}\right), 1.02$ $\left(3 \mathrm{H}, \mathrm{s}, \mathrm{CH}_{3}\right), 1.07\left(3 \mathrm{H}, \mathrm{s}, \mathrm{CH}_{3}\right), 1.68\left(3 \mathrm{H}, \mathrm{s}, \mathrm{CH}_{3}\right), 1.86$ $(1 \mathrm{H}, \mathrm{m}, \mathrm{OH}), 2.56(1 \mathrm{H}, \mathrm{m}, \mathrm{H}-19), 3.27(1 \mathrm{H}, \mathrm{m}, \mathrm{OH}), 3.40$ $(1 \mathrm{H}, \mathrm{m}, \mathrm{OH}), 3.45(1 \mathrm{H}, \mathrm{m}, \mathrm{OH}), 3.71(1 \mathrm{H}, \mathrm{m}, \mathrm{CH}$-sugar $)$, $3.85(1 \mathrm{H}, \mathrm{m}, \mathrm{CH}$-sugar), $4.04(1 \mathrm{H}, \mathrm{d}, J=10.8 \mathrm{~Hz}, \mathrm{H}-28)$, $4.56(1 \mathrm{H}, \mathrm{d}, J=10.8 \mathrm{~Hz}, \mathrm{H}-28), 4.59(1 \mathrm{H}, \mathrm{s}, \mathrm{H}-29), 4.63$ $(1 \mathrm{H}, \mathrm{m}, \mathrm{CH}$-sugar), $4.74(1 \mathrm{H}, \mathrm{s}, \mathrm{H}-29), 5.20(1 \mathrm{H}, \mathrm{d}, J=$ $5.4 \mathrm{~Hz}, \mathrm{CH}$-sugar), $5.34(1 \mathrm{H}, \mathrm{d}, J=5.4 \mathrm{~Hz}, \mathrm{CH}$-sugar $), 5.45$ $(1 \mathrm{H}, \mathrm{d}, J=5.4 \mathrm{~Hz}, \mathrm{CH}$-sugar), $5.62(1 \mathrm{H}, \mathrm{d}, J=5.4 \mathrm{~Hz}, \mathrm{CH}-$ sugar), $9.08\left(1 \mathrm{H}, \mathrm{s}, \mathrm{CH}\right.$-triazole); ${ }^{13} \mathrm{C}$ NMR $(150 \mathrm{MHz}$, DMSO-d $_{6}$ ): $\delta 14.9,15.8,16.1,19.3,19.6,21.2,21.3,25.2$, $26.8,27.1,29.4,29.6,33.4,34.1,34.6,36.8,37.1,39.3$, $42.8,46.8,47.0,47.5,48.7,49.4,54.3,61.2,62.6,69.9$, $72.4,77.2,79.6,80.6,88.3,110.5,129.1,139.2,150.3$, $160.9, \quad 218.0 ; \quad$ HRAPCIMS $\mathrm{m} / \mathrm{z} \quad$ (neg): 696.4220 $\mathrm{C}_{39} \mathrm{H}_{58} \mathrm{~N}_{3} \mathrm{O}_{8}$ (calcd. 696.4224).

\section{8-(1-Ethylacetyl-1H-1,2,3-triazol-4-yl)carbonylbetulone}

(6g) Yield 79\%; m.p. 97-99 ${ }^{\circ} \mathrm{C}$; IR (KBr) $\nu_{\max } 3147$, 2945, 1755, 1705, 1541, 1458, 1211-1111 cm $\mathrm{cm}^{-1}$; $\mathrm{H}$ NMR $\left(600 \mathrm{MHz}, \mathrm{CDCl}_{3}\right): \delta 0.88\left(3 \mathrm{H}, \mathrm{s}, \mathrm{CH}_{3}\right), 0.93\left(3 \mathrm{H}, \mathrm{s}, \mathrm{CH}_{3}\right)$, $0.95\left(3 \mathrm{H}, \mathrm{s}, \mathrm{CH}_{3}\right), 1.00\left(3 \mathrm{H}, \mathrm{s}, \mathrm{CH}_{3}\right), 1.03\left(3 \mathrm{H}, \mathrm{s}, \mathrm{CH}_{3}\right)$, $1.26\left(3 \mathrm{H}, \mathrm{t}, J=7.2 \mathrm{~Hz}, \mathrm{CH}_{3}\right), 1.68\left(3 \mathrm{H}, \mathrm{s}, \mathrm{CH}_{3}\right), 2.45(1 \mathrm{H}$, $\mathrm{m}, \mathrm{H}-19), 4.10(1 \mathrm{H}, \mathrm{d}, J=10.8 \mathrm{~Hz}, \mathrm{H}-28), 4.23(2 \mathrm{H}, \mathrm{q}, J=$ $\left.7.2 \mathrm{~Hz}, \mathrm{OCH}_{2}\right), 4.51(1 \mathrm{H}, \mathrm{d}, J=10.8 \mathrm{~Hz}, \mathrm{H}-28), 4.54(1 \mathrm{H}$, $\mathrm{s}, \mathrm{H}-29), 4.65(1 \mathrm{H}, \mathrm{s}, \mathrm{H}-29), 5.15\left(2 \mathrm{H}, \mathrm{s}, \mathrm{CH}_{2}\right), 8.16(1 \mathrm{H}, \mathrm{s}$, CH-triazole); ${ }^{13} \mathrm{C}$ NMR $\left(150 \mathrm{MHz}, \mathrm{CDCl}_{3}\right): \delta 14.2,14.7$, $15.9,19.6,21.1,21.3,25.2,26.6,27.1,29.6,29.8,33.5$, $34.2,34.7,36.9,37.8,39.6,40.9,42.8,46.7,47.4,47.7$, 48.8, 49.7, 51.0, 55.0, 60.4, 62.8, 63.6, 110.0, 128.7, 140.7, 150.1, 160.9, 165.7, 171.2, 218.1; HRAPCIMS $\mathrm{m} / \mathrm{z}$ (neg): $620.4049 \mathrm{C}_{37} \mathrm{H}_{54} \mathrm{~N}_{3} \mathrm{O}_{5}$ (calcd. 620.4063).

28-[1-(3-Hydroxypropyl)-1H-1,2,3-triazol-4-yl]carbonylbetulone (6h) Yield 78\%; m.p. $197-199{ }^{\circ} \mathrm{C}$; IR (KBr) $\nu_{\max }$ $3404,2960,1735,1703,1543,1458,1261-1223 \mathrm{~cm}^{-1} ;{ }^{1} \mathrm{H}$ NMR $\left(600 \mathrm{MHz}, \mathrm{DMSO}-\mathrm{d}_{6}\right): \delta 0.88\left(3 \mathrm{H}, \mathrm{s}, \mathrm{CH}_{3}\right), 0.94(3 \mathrm{H}$, s, $\left.\mathrm{CH}_{3}\right), 0.99\left(3 \mathrm{H}, \mathrm{s}, \mathrm{CH}_{3}\right), 1.00\left(3 \mathrm{H}, \mathrm{s}, \mathrm{CH}_{3}\right), 1.05(3 \mathrm{H}, \mathrm{s}$, $\left.\mathrm{CH}_{3}\right), 1.10\left(2 \mathrm{H}, \mathrm{m}, \mathrm{CH}_{2}\right), 1.67\left(3 \mathrm{H}, \mathrm{s}, \mathrm{CH}_{3}\right), 2.52(1 \mathrm{H}, \mathrm{m}$, $\mathrm{H}-19), 3.38\left(2 \mathrm{H}, \mathrm{m}, \mathrm{CH}_{2}\right), 4.02(1 \mathrm{H}, \mathrm{d}, J=10.8 \mathrm{~Hz}, \mathrm{H}-28)$, $4.48\left(2 \mathrm{H}, \mathrm{t}, J=7.2 \mathrm{~Hz}, \mathrm{CH}_{2}\right), 4.55(1 \mathrm{H}, \mathrm{d}, J=10.8 \mathrm{~Hz}, \mathrm{H}-$ 28), $4.59(1 \mathrm{H}, \mathrm{s}, \mathrm{H}-29), 4.74(1 \mathrm{H}, \mathrm{s}, \mathrm{H}-29), 8.81(1 \mathrm{H}, \mathrm{s}, \mathrm{CH}-$ triazole); ${ }^{13} \mathrm{C}$ NMR $\left(150 \mathrm{MHz}\right.$, DMSO-d $\left.\mathrm{d}_{6}\right): \delta 14.9,15.8$, $16.1,19.2,19.5,21.2,21.3,25.2,26.8,27.1,29.4,29.6$, $33.1,33.4,34.1,34.6,36.8,37.7,39.3,42.8,46.8,47.0$, $47.5,47.6,48.6,49.3,54.3,57.8,62.5,79.6,110.5,129.7$, 
139.0, $150.3161 .0, \quad 217.0 ; \quad$ HRAPCIMS $\mathrm{m} / \mathrm{z} \quad$ (neg): 592.4131 $\mathrm{C}_{36} \mathrm{H}_{54} \mathrm{~N}_{3} \mathrm{O}_{4}$ (calcd. 592.4114).

2-Amino-3-[4-(3-acetyl-28-betulonylcarbonyl)-1 H-1,2,3-triazol-1-yl]propanoic acid (6i) Yield $48 \%$; $163-166^{\circ} \mathrm{C}$; IR (KBr) $\nu_{\max } 3479,2956,1732,1705,1606,1456$, $1280-1223 \mathrm{~cm}^{-1}$; ${ }^{1} \mathrm{H}$ NMR $(600 \mathrm{MHz}$, DMSO-d 6 ) $\delta: 0.85$ $\left(3 \mathrm{H} \mathrm{s}, \mathrm{CH}_{3}\right), 0.89\left(3 \mathrm{H}, \mathrm{s}, \mathrm{CH}_{3}\right), 0.98\left(3 \mathrm{H}, \mathrm{s}, \mathrm{CH}_{3}\right), 1.02$ $\left(3 \mathrm{H}, \mathrm{s}, \mathrm{CH}_{3}\right), 1.04\left(3 \mathrm{H}, \mathrm{s}, \mathrm{CH}_{3}\right), 1.07(1 \mathrm{H}, \mathrm{t}, J=7.2 \mathrm{~Hz}$, $\mathrm{CH}), 1.67\left(3 \mathrm{H}, \mathrm{s}, \mathrm{CH}_{3}\right), 2.51(1 \mathrm{H}, \mathrm{m}, \mathrm{H}-19), 4.12(1 \mathrm{H}, \mathrm{d}, J$ $=10.8 \mathrm{~Hz}, \mathrm{H}-28), 4.21\left(2 \mathrm{H}, \mathrm{d}, J=7.2 \mathrm{~Hz}, \mathrm{CH}_{2}\right), 4.56(1 \mathrm{H}$, $\mathrm{d}, J=10.8 \mathrm{~Hz}, \mathrm{H}-28), 4.59(1 \mathrm{H}, \mathrm{s}, \mathrm{H}-29), 4.74(1 \mathrm{H}, \mathrm{s}, \mathrm{H}-$ 29), $8.62(1 \mathrm{H}, \mathrm{s}, \mathrm{CH}$-triazole $) ;{ }^{13} \mathrm{C}$ NMR $(150 \mathrm{MHz}$, DMSO- $\left.\mathrm{d}_{6}\right): \delta 14.3,15.0,16.1,16.3,16.9,21.5,22.9,23.7$, $28.1,28.8,30.2,37.1,37.8,38.5,39.5,40.8,42.8,67.9$, $80.4,110.0,129.1,132.1,132.2,150.1,167.5,217.1$; HRAPCIMS $\mathrm{m} / \mathrm{z}$ (neg): $621.4050 \quad \mathrm{C}_{36} \mathrm{H}_{53} \mathrm{~N}_{4} \mathrm{O}_{5}$ (calcd. 621.4015).

\section{3-Methyl-3-[4-(28-betulonylcarbonyl)-1H-1,2,3-triazol-1-yl]} butyric acid (6j) Yield 54\%; m.p. 246-249 ${ }^{\circ} \mathrm{C}$; IR (KBr) $\nu_{\max } 3446,2945,1732,1709,1616,1456,1280-1211 \mathrm{~cm}$

${ }^{-1} ;{ }^{1} \mathrm{H}$ NMR $\left(600 \mathrm{MHz}\right.$, DMSO-d $\left.\mathrm{d}_{6}\right) \delta: 0.72\left(3 \mathrm{H}, \mathrm{s}, \mathrm{CH}_{3}\right)$, $0.87\left(3 \mathrm{H}, \mathrm{s}, \mathrm{CH}_{3}\right), 0.96\left(3 \mathrm{H}, \mathrm{s}, \mathrm{CH}_{3}\right), 1.00(3 \mathrm{H}, \mathrm{d}, J=$ $\left.6.6 \mathrm{~Hz}, \mathrm{CH}_{3}\right), 1.01\left(3 \mathrm{H}, \mathrm{s}, \mathrm{CH}_{3}\right), 1.04\left(3 \mathrm{H}, \mathrm{s}, \mathrm{CH}_{3}\right), 1.08$ $\left(3 \mathrm{H}, \mathrm{d}, J=6.6 \mathrm{~Hz}, \mathrm{CH}_{3}\right), 1.68\left(3 \mathrm{H}, \mathrm{s}, \mathrm{CH}_{3}\right), 2.43(1 \mathrm{H}, \mathrm{m}$, $\mathrm{CH}), 2.53(1 \mathrm{H}, \mathrm{m}, \mathrm{H}-19), 4.03(1 \mathrm{H}, \mathrm{d}, J=10.8 \mathrm{~Hz}, \mathrm{H}-28)$, $4.28(1 \mathrm{H}, \mathrm{m}, \mathrm{CHCOOH}), 4.55(1 \mathrm{H}, \mathrm{d}, J=10.8 \mathrm{~Hz}, \mathrm{H}-28)$, $4.64(1 \mathrm{H}, \mathrm{s}, \mathrm{H}-29), 4.74(1 \mathrm{H}, \mathrm{s}, \mathrm{H}-29), 8.76(1 \mathrm{H}, \mathrm{s}, \mathrm{CH}-$ triazole); ${ }^{13} \mathrm{C}$ NMR $(150 \mathrm{MHz}$, DMSO-d 6$) \delta: 14.3,14.6$, $14.9,15.8,16.0,16.1,18.9,19.2,19.6,19.9,21.2,25.2$, $26.8,27.1,29.5,29.7,30.8,33.4,34.1,36.8,37.7,39.3$, $40.8,42.8,46.8,47.0,47.5,48.6,49.3,54.3,62.6,79.7$, 110.5, 129.4, 138.7, 150.3, 161.3, 217.1; HRAPCIMS m/z (neg): $535.3878 \mathrm{C}_{35} \mathrm{H}_{51} \mathrm{O}_{4}$ (calcd. 535.3865).

\section{Biological study}

\section{Cells}

The triterpenes were evaluated for their cytotoxic activity towards three human cancer cell lines: amelanotic melanoma C-32 (ATCC, Rockville, USA), ductal carcinoma T47D (ATCC, Rockville, USA) and glioblastoma SNB-19 (DSMZ, Braunschweig, Germany). The cells were seeded in 96-well plates (Nunc Thermo Fisher Scientific, Waltham, USA) at a density of $5 \times 10^{3}$ cells per well and maintained for $24 \mathrm{~h}$ at $37{ }^{\circ} \mathrm{C}$ in a humid atmosphere saturated with $5 \%$ $\mathrm{CO}_{2}$. All cancer cell lines were cultured in DMEM (Lonza, Basel, Switzerland) growth medium containing 10\% fetal bovine serum (FBS) (Biological Industries, Cromwell, USA), penicillin $(10,000 \mathrm{U} / \mathrm{mL})$ and streptomycin $(10 \mathrm{mg} /$ $\mathrm{mL}$ ) (Lonza, Basel, Switzerland).
WST-1 assay

A WST-1 assay (Roche Diagnostics GmbH, Mannheim, Germany) was used for the evaluate of cytotoxicity against the tested human cancer cell lines. The WST-1 assay was carried out after $72 \mathrm{~h}$ incubation of the cells with concentrations ranging from 1 to $100 \mu \mathrm{g} / \mathrm{mL}$ of the tested compounds. The WST-1 tetrazolium salt [sodium 2-(4iodophenyl)-3-(4-nitrophenyl)-5-(2,4-disulfophenyl)-2Htetrazolium] is reduced by mitochondrial dehydrogenases of viable cells to water-soluble formazan. The amount of formazan produced by viable cells was quantified by measuring the absorbance $(\lambda=450 \mathrm{~nm})$. The anticancer activity of triterpenes were expressed as an $\mathrm{IC}_{50}$ in $\mu \mathrm{M}$ (Table 2).

\section{Lipophilicity studies}

The theoretical lipophilicity parameters of triazoles $\mathbf{5 a}-\mathbf{i}$ and 6a-j were calculated using the commercially available ALOGPS 2.1 software program (Tetko et al. 2005) (Table $3)$.

\section{Results and discussion}

\section{Chemistry}

The synthesis of triazoles was started from betulin $\mathbf{1}$ and 3acetylbetulin 2 (Fig. 1). Acetylation of betulin $\mathbf{1}$ at the C-3 and $\mathrm{C}-28$ positions with acetic anhydride in the presence of 4-dimethylaminopyridine in pyridine gave betulin 3,28diacetate. A selective hydrolysis of betulin 3,28-diacetate at C-28 position (MeOH/NaOH/THF) afforded 3acetylobetulin 2 with a quantitative yield (Thibeault et al. 2007; Santos et al. 2010).

Subsequently, triterpenes 1-2 were used to prepare the propynoylated derivatives 3-4 according to our published procedures (Boryczka et al. 2013). The triazoles 5a-i and 6a-j were obtained by CuAAC reactions of acetylenic esters with various organic azides in toluene with yields in the range of $45-87 \%$. Synthesis of triazoles $\mathbf{5 a - i}$ and $\mathbf{6 a - j}$ was depicted in Scheme 1. New compounds were purified by column chromatography on silica gel in $\mathrm{CHCl}_{3}-\mathrm{EtOH}$ or $\mathrm{CH}_{2} \mathrm{Cl}_{2}-\mathrm{EtOH}$ with various ratios. The chemical characterization of all derivatives was carried out by ${ }^{1} \mathrm{H}-,{ }^{13} \mathrm{C}$ NMR, IR spectroscopies, and HRMS spectra.

In the ${ }^{1} \mathrm{H}$ NMR spectra of the triazoles 5a-d and 6a-d, singlets of methylene group were observed at $\delta 5.48-5.69$, which suggests the presence of a bond between C-4 (aryl group) and $\mathrm{N}-1$ of the triazole ring. The signals in the range of $\delta$ 7.01-7.72 were assigned to the aromatic protons of the aryl group of derivatives 5a-d and 6a-d. Additionally, for all derivatives 5a-i and 6a-j, signals at $\delta$ 7.96-9.08 were 
Table 2 Anticancer activity $\left(\mathrm{IC}_{50}\right)$ of acetylenic esters 3-4, triazoles of triterpenes 5a-i and $\mathbf{6 a - j}$ and cisplatin as a reference compound against the tested human cancer cell lines

\begin{tabular}{|c|c|c|c|c|}
\hline \multirow[t]{2}{*}{ Compound } & \multirow[t]{2}{*}{ Chemical structure } & \multicolumn{3}{|c|}{ Human Cell Line $/ \mathrm{IC}_{50} \pm \mathrm{SD}[\mu \mathrm{M}]$} \\
\hline & & C-32 & T47D & SNB-19 \\
\hline 3 & & $0.39 \pm 0.05$ & Neg & $0.67 \pm 0.09$ \\
\hline 4 & & $0.01 \pm 0.001$ & $50.75 \pm 0.73$ & $0.19 \pm 0.06$ \\
\hline $5 \mathbf{a}$ & & $2.78 \pm 0.61$ & Neg & $49.91 \pm 0.61$ \\
\hline $5 \mathbf{b}$ & & $0.74 \pm 0.09$ & Neg & $0.85 \pm 0.07$ \\
\hline $5 c$ & & Neg & Neg & Neg \\
\hline 5d & & $6.64 \pm 0.55$ & Neg & $66.04 \pm 1.53$ \\
\hline $5 e$ & & $90.63 \pm 5.73$ & $62.56 \pm 1.00$ & $58.85 \pm 0.48$ \\
\hline $5 f$ & & $59.52 \pm 0.58$ & $44.25 \pm 1.17$ & $52.93 \pm 1.01$ \\
\hline $5 \mathrm{~g}$ & & $0.57 \pm 0.08$ & Neg & $0.78 \pm 0.09$ \\
\hline $5 \mathbf{h}$ & & $18.86 \pm 1.30$ & $24.36 \pm 1.37$ & $7.75 \pm 0.47$ \\
\hline $5 \mathbf{i}$ & & $21.84 \pm 1.42$ & $45.94 \pm 2.10$ & $1.22 \pm 0.60$ \\
\hline
\end{tabular}




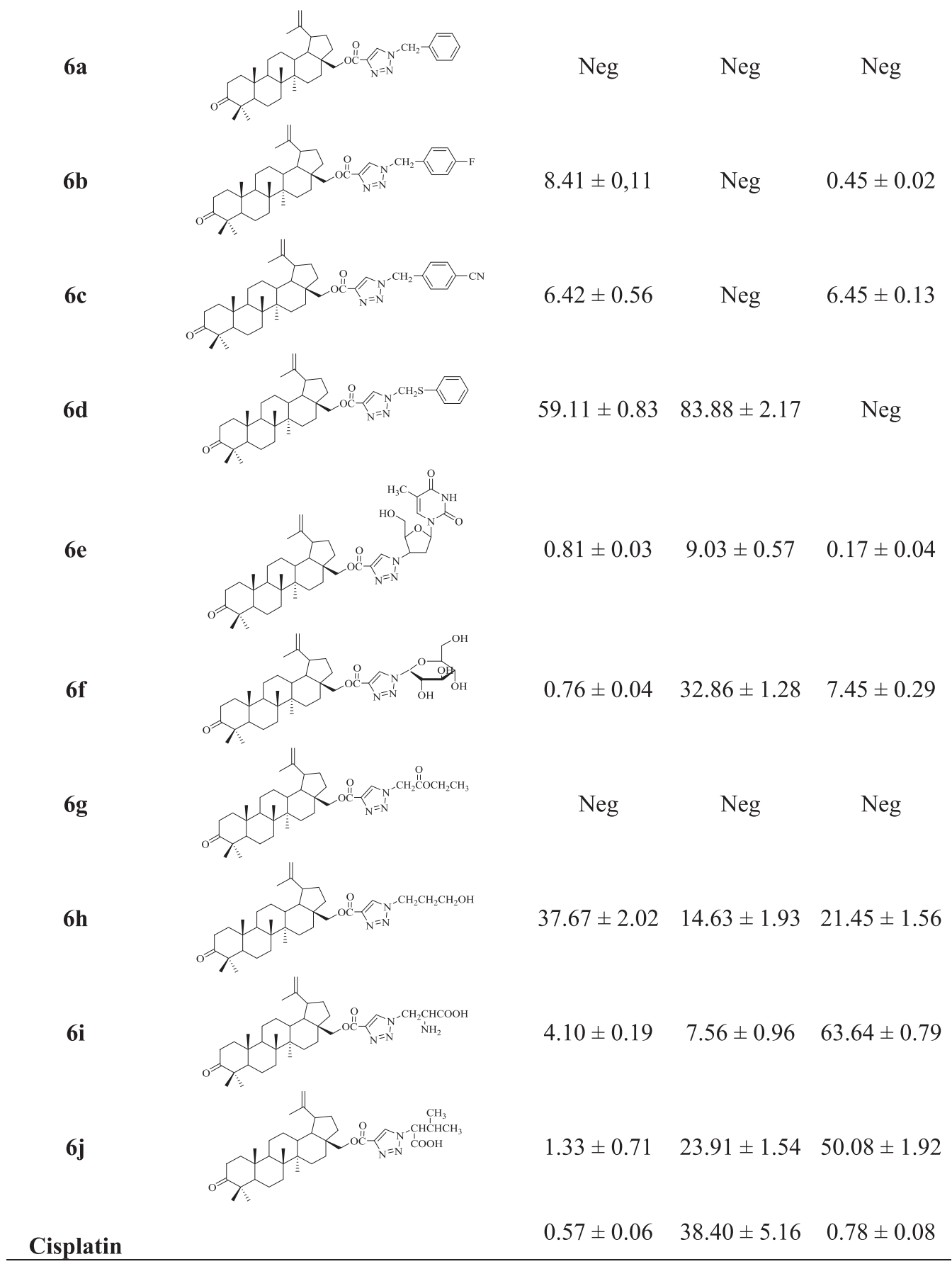

Neg - negative in the concentration used

observed, corresponding to triazolyl protons in the 1,4disubstituted triazole ring.

Analysis of the ${ }^{13} \mathrm{C}$ NMR spectra of triazoles $5 \mathbf{a}-\mathbf{i}$ and 6a-j showed that the signals of acetyl and carbonyl groups are located at $167.5-171.1$ p.p.m. and $217.0-218.1$ p.p.m., respectively.
The IR spectra of new triazoles $5 \mathbf{a}-\mathbf{i}$ and $\mathbf{6 a - j}$ showed characteristic absorption bands at $1527-1616 \mathrm{~cm}^{-1}$ and $1456-1458 \mathrm{~cm}^{-1}$, which were attributed to the $\mathrm{C}=\mathrm{N}$ and the $\mathrm{N}=\mathrm{N}$ stretching vibrations of the triazole ring, respectively.

The HRMS negative mode was applied to identify all new compounds. In the mass spectra of triterpenes $\mathbf{3}, \mathbf{5 a}-\mathbf{i}$, 
Table 3 The values of calculated lipophilicity parameters of compound $\mathbf{5 a}-\mathbf{i}$ and $\mathbf{6 a}-\mathbf{j}$

\begin{tabular}{|c|c|c|c|c|c|c|}
\hline Compound & ALOGPs & $\mathrm{AC} \log \mathrm{P}$ & ALOGP & MLOGP & XLOGP2 & XLOGP3 \\
\hline $5 \mathbf{a}$ & 7.76 & 9.09 & 9.56 & 7.29 & 11.43 & 11.87 \\
\hline $5 \mathbf{b}$ & 6.97 & 7.00 & 9.13 & 7.63 & 10.63 & 10.95 \\
\hline $5 c$ & 6.91 & 7.27 & 8.81 & 6.78 & 10.33 & 10.50 \\
\hline $5 d$ & 7.19 & 9.60 & 9.52 & 7.44 & 11.03 & 11.43 \\
\hline $5 e$ & 5.54 & 4.70 & 6.46 & 4.98 & 7.45 & 8.30 \\
\hline $5 f$ & 4.54 & 3.99 & 5.19 & 3.99 & 6.85 & 6.96 \\
\hline $5 \mathrm{~g}$ & 6.26 & 5.78 & 7.61 & 6.15 & 9.03 & 9.58 \\
\hline $5 \mathrm{~h}$ & 5.85 & 5.75 & 6.87 & 5.98 & 8.55 & 8.80 \\
\hline $5 i$ & 2.66 & 3.80 & 6.22 & 3.03 & 5.44 & 5.53 \\
\hline $6 a$ & 6.62 & 7.13 & 8.51 & 6.78 & 9.26 & 9.89 \\
\hline $6 b$ & 6.50 & 7.19 & 8.72 & 7.14 & 9.43 & 9.99 \\
\hline $6 c$ & 6.58 & 6.94 & 8.39 & 6.39 & 8.99 & 9.61 \\
\hline $6 d$ & 6.78 & 9.28 & 9.10 & 7.05 & 9.69 & 10.54 \\
\hline $6 e$ & 5.04 & 4.38 & 6.04 & 4.56 & 6.11 & 7.41 \\
\hline $6 f$ & 4.16 & 3.67 & 4.77 & 3.56 & 5.50 & 6.07 \\
\hline $6 \mathrm{~g}$ & 5.90 & 5.45 & 7.20 & 5.72 & 7.68 & 8.69 \\
\hline $6 h$ & 5.54 & 5.43 & 6.45 & 5.57 & 7.20 & 7.91 \\
\hline $6 \mathbf{i}$ & 2.37 & 3.47 & 5.80 & 2.59 & 4.10 & 4.64 \\
\hline $6 \mathbf{j}$ & 6.21 & 6.00 & 7.82 & 5.90 & 8.12 & 9.36 \\
\hline
\end{tabular}

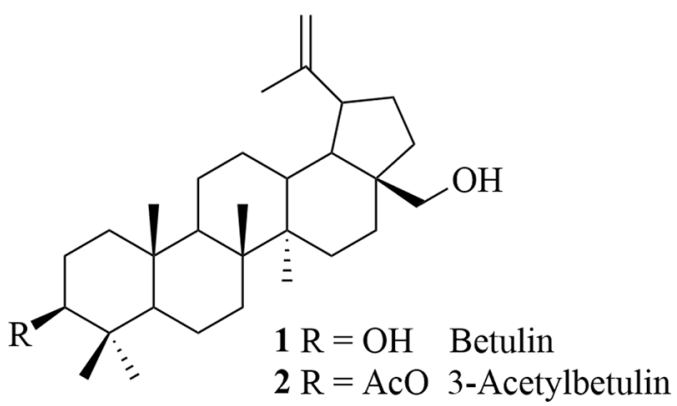

Fig. 1 Chemical structure of betulin 1 and 3-acetylbetulin 2

and 6a-j signals based on ions $[\mathrm{M}-\mathrm{H}]^{-}$were observed. These signals were corresponding to the calculated values.

\section{Biological study}

The triazole derivatives of 3-acetylbetulin and betulone were evaluated in vitro for their anticancer activity using a WST-1 assay against three human cancer cell lines: amelanotic melanoma C-32, ductal carcinoma T47D and glioblastoma SNB-19. Cisplatin was used as a positive control. The results of the anticancer activity tests of the studied compounds are reported in Table 2 as $\mathrm{IC}_{50}(\mu \mathrm{M})$.

As shown in Table 2, the lowest anticancer activity $\left(\mathrm{IC}_{50}\right.$ $7.56-83.88 \mu \mathrm{M})$ of targeted triazoles was observed in the case of the T47D ductal carcinoma cell line. In the tested group of triazoles, derivative $\mathbf{6 i}$ exhibited a highest anticancer activity $\left(\mathrm{IC}_{50} 7.56 \mu \mathrm{M}\right)$ against the $\mathrm{T} 47 \mathrm{D}$ cells, when compared to the positive control.

For triazoles of 3-acetylbetulin 5a-i, the rank order of the anticancer activity towards the C-32 cell line is as follows: $\mathbf{5 g}>\mathbf{5 b}>\mathbf{5 a}>\mathbf{5 d}>\mathbf{5 h}>\mathbf{5 i}>\mathbf{5 f}>\mathbf{5 e}>\mathbf{5 c}$. The compound $5 \mathrm{~g}$ containing a 1-ethylacetyl moiety in triazole ring had the same anticancer activity against the C-32 cell line as the reference cisplatin $\left(\mathrm{IC}_{50} 0.57 \mu \mathrm{M}\right)$. Moreover, triazoles $\mathbf{5 c}$, 6a, and $\mathbf{6 g}$ had no anticancer activity towards C-32 cell line in the applied concentration range.

According to our studies, compounds $5 \mathbf{b}, 5 \mathrm{~g}, 6 \mathbf{b}$, and $6 \mathbf{e}$ showed a significant activity against human glioblastoma SNB-19 cell line, with $\mathrm{IC}_{50}$ values from 0.17 to $0.85 \mu \mathrm{M}$.

The triazole 6e bearing a 3'-deoxythymidine-5'-yl moiety showed the highest activity in the tested group of compounds against SNB-19 cells, with $\mathrm{IC}_{50}$ value of $0.17 \mu \mathrm{M}$.

Our studies suggest, that the introduction of acetyl or carbonyl group at the $\mathrm{C}-3$ position of triazole derivatives of triterpenes afforded compounds having a higher anticancer activity against amelanotic melanoma $\mathrm{C}-32$ cell line. Additionally, the compounds $\mathbf{5 f}$ and $\mathbf{6 f}$ containing the 1deoxy- $\beta$-D-glucopyranosyl substituted triazole ring had a better activity than their parent 3-hydroxyl substituted analogs against C-32, T47D, and SNB-19 cell lines (Bębenek et al. 2017). 


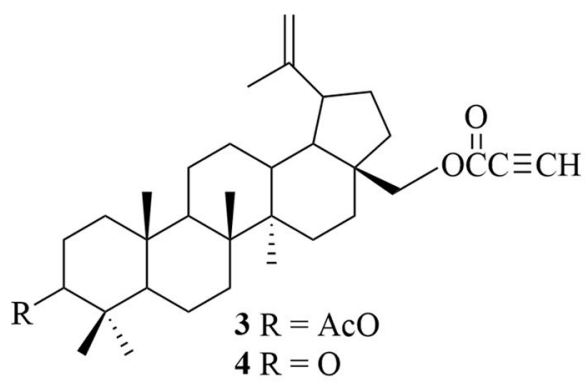<smiles></smiles>

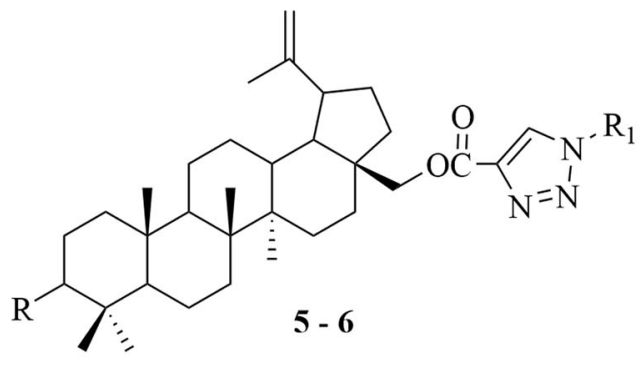<smiles>[R7]Cc1ccccc1C[R17]=[Pt]</smiles>

6a-j $R=O$<smiles>[R7]=CC(=O)OCC</smiles>

h $\mathrm{R}_{1}=\mathrm{CH}_{2} \mathrm{CH}_{2} \mathrm{CH}_{2} \mathrm{OH}$

i $\mathrm{R}_{1}=\mathrm{CH}_{2} \mathrm{CHCOOH}$<smiles>[NH3+]</smiles><smiles>[R7]C(C)C(=O)O</smiles>

Scheme 1 Synthesis of triazole derivatives $5 \mathbf{a}-\mathbf{i}$ and $\mathbf{6 a - j}$. Reagents and conditions: organic azide $\left(\mathrm{RN}_{3}\right), \mathrm{CuI}$, reflux, $72 \mathrm{~h}$

The lipophilicity is one of the important physicochemical parameters in drug development (Andric and Héberger 2015). A lipophilicity study of the tested triazoles was carried out using the ALOGPS 2.1 software program. The predicted $\log \mathrm{P}$ values were calculated according to the molecular structures of triazoles $\mathbf{5 a}-\mathbf{i}$ and $\mathbf{6 a}-\mathbf{j}$ using six computational methods (ALOGPs, AC $\log$, ALOGP, MLOGP, XLOGP2, and XLOGP3). Considering two triazoles of betulone $\mathbf{6 d}$ and $\mathbf{6 e}$, it was observed that their cytotoxic activity increased with the decreasing value of theoretical $\log P$.

\section{Conclusion}

In conclusion, on the basis of the CuAAC reaction, a series of new derivatives of 3-acetylbetulin and betulone bearing 1,2,3-triazole moiety has been synthesized. The anticancer activity of the triazoles and cisplatin was tested against the C-32, T47D and SNB-19 cancer cell lines using the WST-1 assay. The triazole 6e with 3'-deoxythymidine-5'-yl substituent proved to be a potent cytotoxic agent with $\mathrm{IC}_{50}$ value of $0.17 \mu \mathrm{M}$ in the case of the human glioblastoma SNB-19 cell line. Morever, the triazole 6e can be considered as a promising candidate for anticancer therapy.

Acknowledgements This work was supported by the Medical University of Silesia in Katowice, Poland. Grant No KNW-1-015/K/7/0.

\section{Compliance with ethical standards}

Conflict of interest The authors declare that they have no conflict of interest.

Open Access This article is distributed under the terms of the Creative Commons Attribution 4.0 International License (http://crea tivecommons.org/licenses/by/4.0/), which permits use, duplication, adaptation, distribution, and reproduction in any medium or format, as long as you give appropriate credit to the original author(s) and the source, provide a link to the Creative Commons license, and indicate if changes were made.

\section{References}

Andrić F, Héberger K (2015) Towards better understanding of lipophilicity: assessment of in silico and chromatographic $\log \mathrm{P}$ measures for pharmaceutically important compounds by nonparametric rankings. J Pharm Biomed Anal 115:183-191

Bębenek E, Jastrzębska M, Kadela-Tomanek M, Chrobak E, Orzechowska B, Zwolińska K, Latocha M, Mertas A, Czuba Z, Boryczka S (2017) Novel triazole hybrids of betulin: synthesis and biological activity profile. Molecules 22:1876-1892

Bębenek E, Kadela-Tomanek M, Chrobak E, Wietrzyk J, Sadowska J, Boryczka (2016) New acetylenic derivatives of betulin and betulone, synthesis and cytotoxic activity. Med Chem Res 26:1-8

Bonacorso HG, Moraes MC, Wiethan CW, Luz FM, Meyer AR, Zanatta N, Martins MAP (2013) Synthesis of $1 H-1,2,3$-triazolesRufinamide analogs by 1,3-dipolar cycloaddition and eletrocyclization reactions of trifluoroacetyl enolethers under thermal solventless conditions. J Flu Chem 156:112-119 
Boryczka S, Bębenek E, Wietrzyk J, Kempińska K, Jastrzębska M, Kusz J, Nowak M (2013) Synthesis, structure and cytotoxic activity of new acetylenic derivatives of betulin. Molecules $18: 4526-4543$

Bräse S, Friedrich A, Gartner M M, Schröder T (2008) Cycloaddition reactions of azides including bioconjugation. Top Heterocycl Chem 12:45-115

Dheer D, Singh V, Shankar R (2017) Medicinal attributes of 1,2,3triazoles: current developments. Bioorg Chem 71:30-54

He Y-W, Dong C-Z, Zhao J-Y, Ma L-L, Li Y-H, Aisa HA (2014) 1,2,3-Triazole-containing derivatives of rupestonic acid: clickchemical synthesis and antiviral activities against influenza viruses. Eur J Med Chem 76:245-255

Khan I, Guru SK, Rath SK, Chinthakindi PK, Singh B, Koul S, Bhushan S, Sangwan PL (2016) A novel triazole derivative of betulinic acid induces extrinsic and intrinsic apoptosis in human leukemia HL-60 cells. Eur J Med Chem 108:104-116

Majeed R, Sangwan PL, Chinthakindi PK, Khan I, Dangroo NA, Thota N, Hamid A, Sharma PR, Saxena AK, Koul S (2013) Synthesis of 3-O-propargylated betulinic acid and its 1,2,3-triazoles as potential apoptotic agents. Eur J Med Chem 63:782-792

Marciniec K, Latocha M, Kurczab R, Boryczka S (2017) Synthesis and anticancer activity evaluation of a quinoline-based 1,2,3triazoles. Med Chem Res 26:2432-2442

Rostovtsev HV, Green LG, Fokin VV, Sharpless KB (2002) A stepwise huisgen cycloaddition process: copper (I)-catalyzed regioselective "ligation" of azides and terminal alkynes. Angew Chem Int Ed Engl 41:2596-2599

Santos RC, Salvador JAR, Marín S, Cascate M, Moreira JN, Dini TCP (2010) Synthesis and structure-activity relationship study of novel cytotoxic carbamate and $\mathrm{N}$-acylheterocyclic bearing derivatives of betulin and betulinic acid. Bioorganic Med Chem 18:4385-4396

Spivak AY, Gubaidullin RR, Galimshina ZR, Nedopekina DA, Odinokov VN (2016) Effective synthesis of novel C(2)-propargyl derivatives of betulinic and ursolic acids and their conjugation with $\beta$-D-glucopyranoside azides via click chemistry. Tetrahedron 71:1249-1256

Suman P, Patel A, Solano L, Jampana G, Gardner ZS, Holt CM, Jonnalagadda SC (2016) Synthesis and cytotoxicity of BaylisHillman template derived betulinic acid-triazole conjugates. Tetrahedron 73:4214-4226

Tetko IV, Gasteiger J, Todeschini R, Mauri A, Livingstone D, Ertl P, Palyulin VA, Radchenko EV, Zefirov NS, Makarenko AS, Tanchuk VY, Prokopenko VV (2005) Virtual computational chemistry laboratory-design and description. J Comput Aid Mol Des 19:453-463

Thibeault D, Gauthier C, Legault J, Bouchard J, Dufour P, Pichette A (2007) Synthesis and structure-activity relationship study of cytotoxic germanicane - and lupane-type 3 $\beta$-O-monodesmosidic saponins starting from betulin. Bioorg Med Chem 15:6144-6157

Torne CW, Christensen C, Meldal M (2002) Peptidotriazoles on solid phase: [1,2,3]-triazoles by regiospecific copper(I)-catalyzed 1,3dipolar cycloadditions of terminal alkynes to azides. J Org Chem 67:3057-3064

Totobenazara J, Anthony J, Burke AJ (2015) New click-chemistry methods for 1,2,3-triazoles synthesis: recent advances and applications. Tetrahedron Lett 56:2853-2859

Wang X-L, Wan K, Zhou C-H (2010) Synthesis of novel sulfanilamide-derived 1,2,3-triazoles and their evaluation for antibacterial and antifungal activities. Eur $\mathrm{J}$ Med Chem 45:4631-4639

Wei J, Chen J, Xu J, Cao L, Deng H, Sheng W, Zhang H, Cao W (2012) Scope and regioselectivity of the 1,3-dipolar cycloaddition of azides with methyl 2-perfluoroalkynoates for an easy, metalfree route toperfluoroalkylated 1,2, 3-triazoles. J Flu Chem 133:146-154

Yu F, Wang Q, Zhang Z, Peng Y, Qiu Y, Shi Y, Zheng Y, Xiao S, Wang H, Huang X, Zhu L, Chen K, Zhao C, Zhang C, Yu M, Sun D, Zhang L, Zhou D (2013) Development of oleanane-type triterpenes as a new class of HCV entry inhibitors. J Med Chem 56:4300-4319 